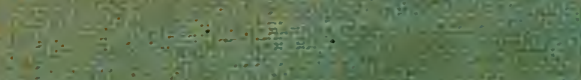

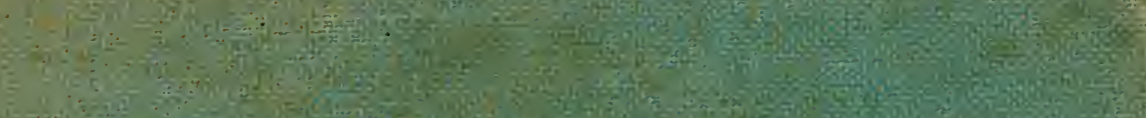

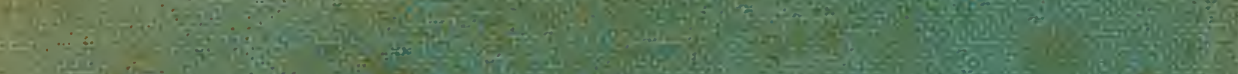
1. in

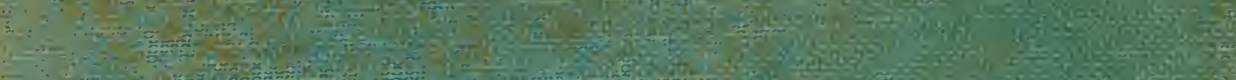

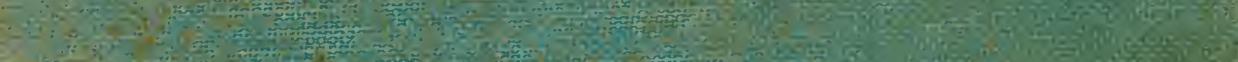
in: i 30 की

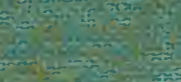

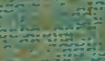

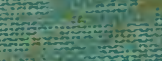

\title{
(1) 14 a
}

-

a

ithis

ra

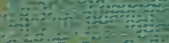

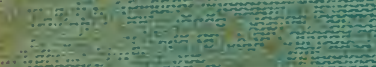

\section{Whand} T. (1)

\section{$+8$} Fin oting

20 (10)

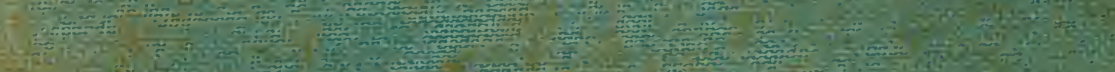

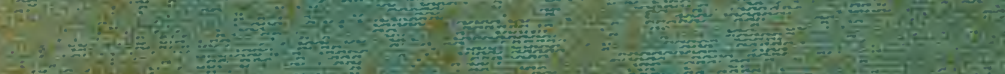

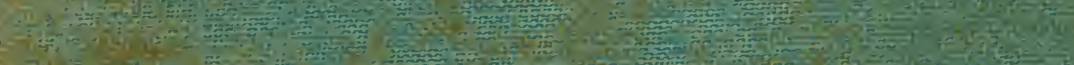

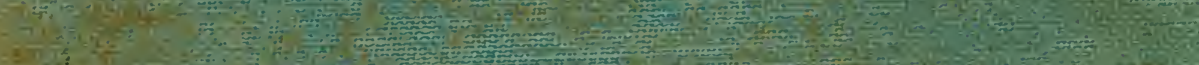

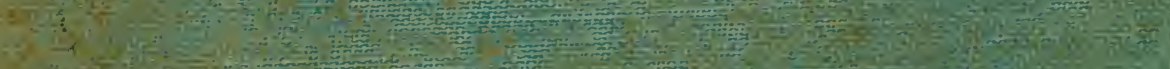

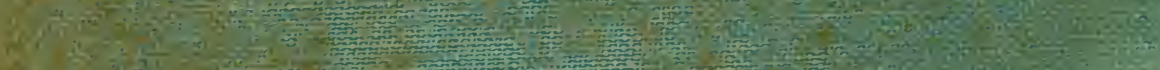




$$
+1.5^{-11}
$$




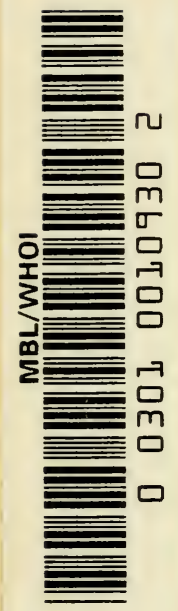







\section{Che Terry $\mathbb{L}_{\mathfrak{c}} \mathrm{etures}$}

\section{THE UNIVERSE AND LIFE}




\section{VOLUMES PUBLISHED BY THE YALE UNIVERSITY PRESS ON THE DWIGHT HARRINGTON TERRY FOUNDATION}

Concerning Evolution.

By J. Arthur Thomson.

Evolution in Science and Religion.

By Robert Andrews Millikan.

The Self: Its Body and Freedom.

By William Ernest Hocking.

Fate and Freedom.

By Henry Norris Russell.

Science and Personality.

By William Brown.

Nature: Cosmic, Human and Divine.

By James Young Simpson.

Belief Unbound: A Promethean Religion for the Modern World.

By Wm. Pepperell Montague.

The Open World: Three Lectures on the Metaphysical Implications of Science.

By Hermann Weyl. 


\title{
THE UNIVERSE
}

\section{AND LIFE}

\author{
H. S. JENNINGS
}

HENRY WALTERS PROFESSOR OF ZOÖLOGY AND DIRECTOR OF THE ZOÖLOGICAL LABORATORY THE JOHNS HOPKINS UNIVERSITY

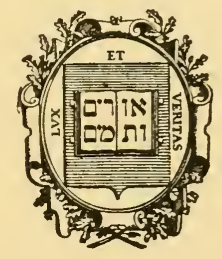

NEW HAVEN - YALE UNIVERSITY PRESS LONDON - HUMPHREY MILFORD - OXFORD UNIVERSITY PRESS 
Copyright 1933 by Yale University Press. Printed in the United States of America.

First published, September, 1933.

Second printing, January, 1934.

All rights reserved. This book may not be reproduced, in whole or in part, in any form (except by reviewers for the public press), without written permission from the publishers. 


\section{CONTENTS}

I. The Nature and Potentialities of the Universe as Revealed by the Study of Biology. The Production of New and Unpredictable Phenomena as Time Passes, including Life and Mind . . . . 1

II. The Nature of the Universe as Revealed by the Study of Biology, continued. Production of New Methods of Action as Well as of New Mental Phenomena. Nature of Evolutionary Progress . . . . . 33

III. The Management of Life . . . . . 67 


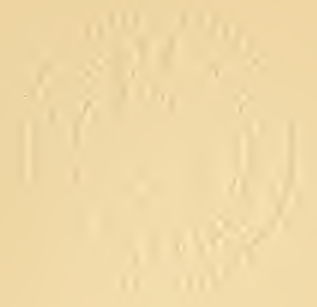


THE NATURE AND POTENTIALITIES OF THE UNIVERSE AS REVEALED BY THE STUDY OF BIOLOGY. THE PRODUCTION OF NEW AND UNPREDICTABLE PHENOMENA AS TIME PASSES, INCLUDING LIFE AND MIND.

T undertaking, at the invitation of Yale University, 1 to give the Terry Lectures having the general subject, "Religion in the Light of Science and Philosophy," I must let you know at the beginning what I understand to be the purpose of the lectures, and what, therefore, I shall try to do.

I shall assume that by religion we mean, for the purpose of these lectures, an attempt to get a unified view of the universe, including man; a unified view that will include the bearings of this unified outlook on the problems of human conduct. I assume that there is no presupposition as to the nature of the views that will be presented; that there is no presumption that they must agree with any views now held under the name of religion or under other names. In past years these lectures have been given successively by a physicist, by an astronomer, by men in other branches of science. This year a biologist is chosen to present them. The intention of thus selecting men from the different sciences is, as I understand it, to bring before you the outlook on the world and man that arises through de- 
votion to a particular science, through examination of a particular aspect of the universe. Each lecturer is to serve as a sample, a specimen, of the results which follow from devoting one's life mainly to a certain field of study. This I take to be one of the main purposes of the lectures: they are to give specimens of the main types of outlook on life and the universe that arise in individuals working in different fields. In the present case, therefore, I am to serve as a specimen of the biologists. I am to present a sample of the results that follow-or that may follow-from devoting one's life to the study of living things.

Of course a specimen is of no use at all unless it is genuine. One must present the views to which he has come just as they are, without holding back anything that may offend his hearers; without any omissions or concessions that are based on conventionalities or that are designed to disarm criticism or opposition; otherwise, the sample is worthless. I shall try to follow these maxims.

And further there must be no striving for novelty or originality at the expense of soundness or sincerity. If the truth is what one is seeking, one cannot reject it because someone else has recognized it or spoken it. It is one's own in the sense that it is the product of one's own experience and thought. But one cannot hope nor wish to be the only person that recognizes the truth. All that one can attempt is to express what seems to him true, irrespective of whether it has or has not seemed true to anyone else. After a lifetime spent in a science, working on the questions that are set by 
the period in which one's life falls, working in accordance with the modes and presuppositions and limitations of that period, at last one wishes to look over the whole, quite irrespective of these modes and presuppositions and limitations; one wishes to come to some preliminary conclusions. Whether these are novel or entertaining or satisfactory to others, whether they agree with the tone of the period in science or elsewhere-all this is quite irrelevant; one merely wishes to discover what seems valid. It is such preliminary conclusions that I shall bring before you. I shall state these conclusions as definitely and clearly as I can, not asserting them dogmatically to be correct, but in order, if possible, to avoid misunderstanding as to their meaning.

Possibly it will turn out that, in the opinion of some of you, what this particular specimen shows is merely how unsatisfactory and objectionable is the outlook to which one comes-at least to which one person has come-through the study of biology. But I must remind you that, even so, the specimen will have served its purpose; and this is a great comfort to the lecturer. He will at least have shown to what sort of errors the study of biology may lead. I must beg of you to keep in mind at all times my function as a specimen; it covers a multitude of sins.

The purpose of these lectures then will be to try to show what positive outlook on life and the world is given by the study of biological science; and how this differs, if at all, from the outlook based on physics, or from the outlook presented in some of the religions of 
the world. We shall have to sketch some of the main features of those aspects of the universe that the biologist studies; the main features of the world of life. We shall try to see the relations of the world of life to the rest of the universe, and what light this casts on the nature of things in general. In connection with this we shall be forced into certain critical remarks on some of the practices and conclusions of science; and also on some of the ideas and practices that are conspicuous in some of the religions of the world. And finally we shall try to see the bearings of all these things on the problems of human conduct and on our attitude toward life and the world.

At the beginning I feel driven to confess that the task of presenting a satisfying unified account of the world and of what goes on in it seems to me very much the sort of task that Alice would have had, if, after her adventures in Wonderland, she were required to present a satisfactory unified account of that realm. The farther one goes into life and the universe, the more of a wonderland one finds them; the more arbitrary and unexpected and improbable become the things that take place in them. And the more hopeless becomes the prospect of giving any thoroughgoing satisfactory or intelligible account of them, of discovering what men think they want when they call for an explanation of them. One cannot be surprised that the wise men of a previous generation-a Huxley, a Leslie Stephen-merely formulated this conviction of the general arbitrariness and ultimate inexplicability 
of things into a doctrine and gave it a Greek namea Greek name that sounds learned and profound, but that means merely ignorance. I am sure that if Alice had been compelled to formulate her philosophy of Wonderland, she would have called it Agnosticism, which means "I don't understand it at all."

Nevertheless, there are certain things that we can do with this confusing world, which help us in dealing with it. We can observe carefully the things that happen in it; we can record them and compare them. We can intervene in them ourselves, we can change the situation of things and discover what happens then; this we call experimenting. We thus discover under what conditions certain things occur; and what differences in the results follow from changing the conditions in certain ways. We thus discover that there are certain uniformities, certain constancies in the changing world. We find that we can, to some extent, classify things and events and their dependence on conditions. In consequence, we can generalize, we can state what we call rules or laws; that is, we can make statements which include several or many things or events in a single proposition. We can say not merely that this object gravitates toward the earth, but that all objects (or at least many of them) gravitate together. We can say, not only that the hereditary characteristics of the fruit fly depend on the nature of its chromosomes, but also that the hereditary characteristics of man and most other animals and plants depend on their chromosomes. We can further make inferences from what we observe, draw conclusions from them; 
and some of these inferences we can test, and discover either that they are true or that they are not true. ${ }^{1}$

As a result of all this, the original chaotic wonderland becomes to our minds in some degree ordered and simplified. All this is what we call science. Science is man's attempt, in the way I have sketched, to order and formulate his experiences. He is compelled to accept the experiences that come to him, and he must order and formulate them only in ways that accord with critical observation and experimentation; and in such a manner that the formulations can be tested and verified. It is in the light of the results of this process that we are to try here to sketch a general outlook on the universe.

To observe, to generalize, to make inferences and to test these inferences-all these, if soundly performed, are included in what we may call positive science, the assured results of scientific inquiry. But in our present enterprise we are venturing beyond these limits. In trying to get a general view of things, we are forced to make some inferences that cannot be tested. So far as we do this, we cannot present the conclusions we thus reach as positive science, we can

1 There is a great difficulty with our generalizations in that we do not know how broad to make them; we do not know how much they cover. The man of science studies a particular phenomenon as representative of a class; he hopes that what is true of this will be true of all the class. But what the limits of the class are is not known. Everything differs in some respect from everything else, and we are not certain what consequences may result from the actual diversities till we have tried them. And to try the consequences of all diversities is not possible. This results in making doubtful or erroneous many of the general conclusions of science. 
present them only as inferences that are based upon positive science and are consistent with it.

One further preliminary point is of great importance for understanding what I shall try to present. If we are to keep in the spirit of science, we must make only inferences of the same kind that we make in positive science, though these inferences may reach out into regions in which it is not possible to test them. This means, in the main, that we must try to limit ourselves to drawing conclusions as to the extension, in space and time, of the same types of things that are observed and dealt with in positive science. For example, we shall have to talk of the probable future of life on the earth and of life elsewhere, and of the changes that life may undergo. To limit our conclusions in this way will be our ideal; it limits our undertaking in very definite ways.

But keeping within these limits, I am myself convinced that the study of biology, the study of living things in their relation to the world, does lead to a definite positive outlook on the matters which we have suggested as included in religion. It does help, it seems to me, in getting a unified view of the universe and of man in his relations with it. It adds some things of great importance to the view of things which physics presents to us. And it helps particularly in the problems of managing life, the problems of conduct, and in determining our attitude toward the world. In order to bring out this outlook and its suggestions, we shall devote ourselves, in this lecture and the next, to outlining a picture of what biology shows us; to the 
important and distinctive features of the world that are discovered through the study of living things.

What outlook on the world, then, does one get by the study of biology?

The materials of biological science-those constituents and aspects of the universe to which the biologist devotes himself-differ so conspicuously from the materials of physical science that men have found it difficult to conceive the two as parts of the same universe. Often the physicist's materials are alone taken as constituting the "real" universe. On the other hand, some have ascribed reality only to the distinctive matters with which the biologist deals. What sort of an outlook do we get if we include both in our view?

The special peculiarities of the material studied by the biologist are seen in the fact that it is this material that asks the questions: What outlook on the universe does the study of biology yield? And what is the relation of this to the outlook presented by the great religions? And it is the biologist's material that attempts to answer these questions. And again, it is from an examination of this biological material, which asks and answers these questions, that the biologist is to get his answer to these questions. The biologist is his own material-not all of it, but a sample of it. I am biological material; you are biological material. This lecture, with myself expounding and yourselves listening and questioning and criticizing, is a typical biological phenomenon. It is things of this sort, among many others, that the biologist examines. 
When you consider this, you see that the biologist has access to his material in two ways. On the one hand, he examines it as does the physicist his material; he observes it, experiments with it, analyzes it, determines its physical texture and properties, its chemical nature. He captures a frog, dissects it, makes muscle preparations, times their contractions, measures the elasticity of the material, studies the proteins of which the muscle is composed. He collects beetles and butterflies, pins them in a box and shows them to his friends. He gets a group of Homo sapiens into a room and watches their behavior while he lectures to them.

On the other hand, the biologist has a more intimate access to a certain sample of his material, for he is himself that sample. Through this fact he discovers certain things about the materials of biological science that he cannot discover by the other method alone. $\mathrm{He}$ may, for example, discover that while the sample is lecturing to the group of Homo sapiens, it is worried and doubtful as to the reception of what it says. At other times, he finds that the sample is relieved and comfortable and happy. In short, he finds that the things to be studied by the biologist include emotions, sensations, impulses, desires. And they include ideas, thoughts, purposes, interest in the rest of the world. The biological specimen plays the part, not only of an actor in the world, but also of an interested spectator of the rest of the world. The specimen observes the world, analyzes it, asks questions about it and tries to answer them. It generalizes, forms theories, devises systems of philosophy and religion. 
Thus the biologist has two sets of data, discovered in somewhat different ways, one set being discoverable only through the fact that the biologist is himself a biological specimen. We shall require some brief method of distinguishing the two ways of discovering facts about biological material. For this purpose I shall use the common words outer and inner. We shall call the method of observing other things and other individuals, as the physicist does, the outer view; while discovering things through the fact that the biologist is himself a biological specimen, we shall call the inner view. And we shall call the things discovered by the outer view, the physical phenomena or aspects, while for the things that are discoverable only by the inner view-by being one's self a biological specimen-we shall use the word mental. There are objections to all these terms, but they may serve. Under the mental, therefore, we shall include sensations, feelings, desires, purposes, thoughts, and kindred phenomena. Whether the two sets of data-the physical and the mental-differ in some other fundamental way, so that they can be said to be different in kind, is a matter with which we need not concern ourselves. The verifiable fact is that the two sets of data exist, and that they are discovered in somewhat different ways.

These two sets of data then are the materials with which the biologist has to deal. But with relation to them, an extraordinary situation has arisen in biological science; a situation that must excite surprise in anyone who is not a technical biologist; but a situation which one must have in mind if he is to understand the 
world picture that is often presented in the name of biological science. This remarkable situation lies in the fact that many biologists-perhaps most biologistscompletely ignore the set of data acquired through the fact that the man of science is himself a biological specimen; completely ignore the sensations, emotions, desires, thoughts, and the like, which each of us discovers in himself. There is a class of biologists, called psychologists, who, in the past, have had the job of dealing precisely with these inner or mental phenomena. But even the psychologists have of late shown a tendency to shirk this job; a tendency to devote themselves exclusively to the outer view of living things. And in the minds of many biologists, their science is, as it were, defined as dealing only with things that can be discovered without consulting one's own private experiences as a biological specimen. Data that are discovered in this latter way, things found by the inner view, are simply omitted from consideration, as if they formed no part of the universe.

The reasons for this situation lie partly in certain theories, but mainly in practical considerations and in certain technical difficulties. The data gathered from self-examination by the biological specimen turn out to be extremely difficult to deal with in a scientific way; extremely difficult to formulate and generalize about and draw conclusions from. Men have despaired of discovering the conditions and course and consequences of these inner phenomena, have despaired of treating them with exactitude and reducing them to a system. And so they have decided to ignore them; to 
act as if the universe did not contain them. They think of science as organized knowledge; as knowledge reduced to a system, and since they are not able to reduce these things to a system, it is concluded that they are not material for science. In consequence, the sensations, desires, emotions, and thoughts that are so vivid in what the biological specimen observes in himself are considered matters with which science has nothing to do.

Now this is all very well for certain practical purposes; it is all very well if the purpose is to pick up as much useful detailed knowledge as quickly as one can. But it will never do if the purpose is to present an adequate picture of living things and of the phenomena that belong to life. Men have of course a right to limit their efforts as they will, and biologists may properly limit their study of life to things of a certain kind. They may, if they choose, exclude from consideration this great field of the inner experiences. But it is clear that when they have done this, they are no longer in a position to give an adequate picture of the nature of life. Biological science, defined as limited to the things discovered in the outer view, does not even attempt to give a complete picture of what occurs in living things. It deals with only a part of the subject. Biological science conceived in this limited way, dealing only with certain selected aspects and phenomena of living things, is in no position to speak for biology at large. It is in no position to paint for us such a picture of life and of the universe containing life as a consideration of all the phenomena of biology must yield. 
Many biologists forget this, they forget the fact that they have deliberately restricted their observation and reasoning to a certain group of phenomena. Ignoring this restriction, they speak positively for biological material in the unrestricted sense. They thus present an imperfect and essentially unsound and incorrect picture of the world of living things. The picture that is thus given is fundamentally different from the picture that is obtained when we include all the phenomena; when we include sensations, emotions, ideas, and other mental characteristics.

For the understanding of the present lectures, it is important to grasp clearly the fact that such a course of action, such an ignoring of the inner phenomena of life, appears to the lecturer to vitiate many of the conclusions drawn by biological investigators and indeed to lead to fundamental errors. When the purpose is, as in the present lectures, to give a general picture of biological things in their relation to the rest of the world, we must include what we discover through both methods of approach. The things we discover through the fact that you and I are biological specimens must be considered on the same basis as the data obtained in other ways.

This is not the only example in science of excluding from consideration certain kinds of data. It is sometimes urged that only what is quantitative is science; all qualitative differences and changes fall outside its scope. Or again we are told that only matter in motion, only mechanism, or only energy, constitutes the field of science; that all experiences or 
phenomena that go beyond these are excluded from science.

It is important to realize, what is often forgotten, that such limitations of the field of science must make the picture of reality that science attempts to give incomplete and therefore misleading. Whoever excludes from science any class of the data of experience thereby proclaims that science cannot present an adequate picture of reality. This is something that one must keep in mind in judging the attempts of men of science to portray the nature of reality or of the universe, for such attempts are often made after entire fields of experience have been excluded from consideration. It is the Nemesis of the struggle for exactitude by the man of science, that it leads him to present a mutilated, merely fractional account of the world as a true and complete picture. Only if the field of science is taken to include all experience can science aspire to present an adequate picture of the world.

We shall therefore include as biology not only the data obtained by observing other individuals and things, but also those that we reach through the fact that we are ourselves biological specimens. We shall include the mental as well as the physical.

And when we do this, the great fact, the striking and characteristic feature of the biologist's picture of the world, is that biological materials include sensations, emotions, desires, hopes and fears, purposes, ideas, interest, thought, imagination, knowledge. Whatever else the universe may be, it is something that brings forth these things. The universe is a sys- 
tem that produces the kind of thing of which the physicist and biologist are samples, of which you and I are samples, including all that we are, all that we experience.

Anyone who tries to make for himself a picture of the world must reckon with this fact. This universe is one that brings forth life, and life includes the inner experiences that we have just mentioned.

When, therefore, we think of electrons, protons, neutrons, atoms, or other elementary constituents of things, our idea of them is incomplete and inadequate in most fundamental ways if we do not include in their properties the production of life when they become combined in certain ways. Among their properties is the production of sensations, emotions, thought, of all the diversified mental experiences which belong to living things, to men. When a group of the elementary particles become joined in certain ways, under certain conditions, they begin to feel, to have knowledge, and to think. This property of the elementary particles could indeed not be known until it was manifested, until they did become combined in such ways as to produce life; but when that occurs, it shows one of the fundamental facts about them, one of the fundamental things about the universe. Life and sensation and thought are not things apart, properties of some extra-mundane spectator of a universe that does not include them; things to be left out of account in the picture of reality, as we sometimes find to be the practice.

On the contrary, life, with its sensations, emotions, 
and the rest, is a constituent feature of the universe on the same basis of reality and "naturalness" as its other features; something that reveals its nature as do its other constituents. Any discussion of the nature of the universe, any picture of its activities that leaves this out of account, is preposterously incomplete, inadequate, and misleading. The universe is a system that brings forth life, sensation, emotion, thought. This will be the keynote of our presentation.

In another respect the material studied by the biologist reveals features that are of the highest interest for our understanding of the nature of things. Viewed either from without or from within, biological material is not "running down" but "running up." It is developing instead of degenerating. The activities of the material which the physicist observes, we are told (in some quarters at least), are running down; are becoming continually more diffused, less contrasted. Its structure and behavior are becoming, on the whole, less complex, less definite. The end that is in sight is a universe of diffused particles, in which nothing occurs but a faint quivering. The physicist's material is dominated by the generalized second law of thermodynamics; in it energy passes, on the whole, from regions of higher intensity to regions of lower intensity. Consequently, energy becomes continually more diffused and equalized, material structures become less sharply defined, until ultimately there must occur a uniform distribution of matter and energy in which nothing happens. 
The biologist's material, on the other hand, is that part of the universe that is not dominated by the second law of thermodynamics. In it energy passes from regions of low intensity to regions of high intensity. Simpler and less differentiated materials build themselves up into complex highly diversified structures with strongly marked and varied activities. Biological material is developing; producing the more complex, the more diversified, the more definite, from that which is simple, uniform, and undefined. Such changes are seen daily in the development of an egg into an adult. They occur in a great historical sequence, extending through ages, in the process of organic evolution.

There is then a part of the natural world, a part of the universe, that develops and builds itself into more complex structures. And this development shows other special features that are of the highest interest for our outlook on the world.

But before we pass to these, certain relations between development in biology and degradation in physics require consideration. The building up of biological material is done at the expense of a degradation of physical material. The building up of plants on the earth is made possible by the dissipation - the loss- of radiative energy from the sun. The building up of animals is made possible by the disintegration of the materials of plants and thus, secondarily, by the dissipation of the sun's energy. In all this building up of biological material, the quantity of physical material degraded, the quantity of 
energy dissipated, is greater than the quantity of biological material built up.

Thus if these are the only processes that occur, and if the universe is finite in the quantity of material and energy it contains, the general result of the two processes together is a lowering of the level of the whole. The universe, taken as containing both biological and physical material, would then, on the whole, be running down. The process of building up biological material at the expense of physical material could not, therefore, go on forever. So, on these assumptions, the building up of biological material must in time come to an end. The universe as a whole would eventually become inactive, dead; life would cease.

But it is not certain that these assumptions are correct. Of late we hear again of the infinity of the universe as a popular doctrine in physics. If the universe is quantitatively infinite, there is the possibility of unending development of living things. And we have seen, in the reports of the recent meetings of the American Association for the Advancement of Science, that there are physicists who hold it probable that, even in physical material, processes of upbuilding occur which are not overbalanced by compensating breakdown. If this turns out to be the case, biological development may continue without end. In the present state of physics, no one can say that the development of life may not continue indefinitely. 
Only a minute fraction of the universe, it appears, has as yet brought forth life. The elementary constituents of the universe, it is certain, are of such a nature that they can and do bring forth life when combined in certain ways. But in only a very small proportion of them have these combinations thus far been formed. Even on our earth, it is but a thin rind that has brought forth life. And, according to the views of some modern astronomers, the conditions for life seem to be present in but few of the heavenly bodies. Yet since the constituents of the universe are of a nature to produce life when rightly combined, the remainder, or some part of the remainder, need but enter into such combinations in order to bring forth life on a vaster scale than has yet occurred.

But it is not the present quantity of life, nor even its unending continuance, that is the chief interest for our outlook on the world. Rather is the interest in the nature of the processes that occur in the living material. What is development? What sort of things are taking place in the development of living beings? Is development a bringing forth of things that are new, or is it the mere operation of a machine? Is the living world embarking on a new adventure, or is it merely treading a mill, following a pattern that exists beforehand? Are the heights to which life rises in evolution new heights not before reached, or does there already exist something higher, an ultimate goal toward which it is all tending? These are ques- 
tions which we wish to examine. To judge of them, we must look now at some features in the rising tide of life.

Development occurs both in the outwardly observable physical features of living things, and in those inner characteristics which we discover through the fact that we are ourselves biological specimens. In the outwardly observable features, we find that the structures and the physiological activities become, as time passes, more and more complex and diversified. At first the living material is relatively simple, amoeba-like. Later it becomes complicated; it transforms into the higher plants and animals. And as it transforms, both its structure and its activities become in a high degree regulatory or adaptive. The activities of the organism are carried on under the stress and pressure of the surrounding physical conditions. The organism indeed lives and acts through and by means of the physical elements and conditions; it is itself an integrated group of such elements and conditions; it is, as it were, a whirlpool through which they flow. Under the accidents and changes of the physical conditions, the organism does not disintegrate; it maintains its unity, its individuality. It turns aside or opposes the currents of physical action in such a way as to maintain its structures and its essential internal processes. It exercises a selective action, admitting those elements and conditions that are favorable to its life processes, rejecting or fleeing from those that are unfavorable. In doing this the organism produces, as time passes, complex machine- 
like structures that operate to bring about such regulatory results : tubes for carrying nutrient fluids, cords for conveying impulses from one part of the body to another, and a thousand other such arrangements.

Many of these structures are such as to bring about a correspondence between things that occur inside the body of the organism, and those that take place outside in the surrounding world. The living thing develops the power to move away from conditions that affect unfavorably its inner life processes and to seek and hold conditions that are favorable. It develops external and internal structures that register the events that occur: the external events that act on it, and the reactions that these induce in the organism itself. It develops sense organs, eyes, and ears that register the outer events; nerves, brain, and other parts that mediate between the external and the internal events and that register the organism's responses to the outer events. Its internal constitution thus comes to depend on the environmental conditions to which the organism has been subjected and on the responses that it has given to those conditions. In consequence, its present activity comes to be dominated in large measure by past conditions and past reactions. There is a tendency in the universe toward uniformity in the sequence of conditions and results; given conditions now tend to produce the same results that they produced at an earlier occurrence. Through this tendency toward uniformity in the outer world, it becomes possible for the organism to become pre- 
pared to meet situations that have not yet arrived; it takes measures that avoid a later danger or that seize a later benefit. The mollusk that reacts to a shadow as it does to an attack, the rat that avoids a trap, the author that prepares a paper for publication, the statesman that guides a nation to a higher state of culture-these illustrate those features of biological material just described.

Thus in the externally observable structures and activities of organisms there are progressive changes which lead to greater complexity, adequacy, adaptiveness.

And along with these, closely correlated with them, occur other changes that are discovered through the fact that the biologist is himself a biological specimen; through the fact that the biologist that studies is a piece of the same material of which are composed the living things that he studies. When in development the organism reaches some degree of elaboration, it has sensations, it feels. As development goes farther and the living things become more complex and diversified in structure, the sensations, feelings, and other inner experiences also become more elaborate and diversified. New mental experiences are added; the mental experiences become in a high degree complex and differentiated. These inner phenomena are highly correlated, not only with the physical make-up of the organism, but also with the physical conditions and changes that act on the organism from outside. A correspondence is induced between these inner processes-that we can discover 
only by being an organism-and the processes in the outer physical world. A sort of reflection of the outer world is generated in what we call knowledge. In connection particularly with long-range regulatory action-that is, in preparing for events that have not yet arrived-the process we call thinking occurs. The correspondence between the direct inner experiences of the organism in thought and the changes occurring in the outer physical material may become so adequate that thinking may yield truth about the outer world. That is, the biological specimen asks questions about the outer world and sometimes may answer them correctly, through taking thought, without subjecting itself to the conditions to which the questions refer. At this stage in development, the biological specimen has purposes, plans their accomplishment, meditates on the world; discusses such questions as religion from the point of view of science.

This process of development, double in aspect, must stir interest and astonishment. It seems to produce the living from the lifeless; the feeling and knowing from the unconscious and inert. It seems to bring forth totally new things, not foreshadowed in what went before. Does it actually do these things? And in particular, what is the rôle of the inner things; sensations, feelings, ideas? Do these affect or change the outer things, the movements that occur, the behavior of things? Are these inner things active agents in the developmental process? To these questions as to the essential nature of development, we now turn. 
It is clear that the characteristic phenomena of living things, both "inner" and "outer" come forth progressively. Calling, for brevity's sake, these characteristic phenomena life, we may say that life is not some single definite thing, existing once and for all. On the contrary, it is at first a relatively simple thing; which indeed at an earlier period apparently did not exist at all but came into being at a particular time-a point to which we return. But, in any case, the relatively simple life of early periods does not remain what it was but changes, becomes something else. It alters quantitatively, passing from conditions of simplicity and diffusiveness to complexity and definiteness.

And more important, it alters qualitatively, in the sensations, feelings, and other phenomena that are directly experienced-the phenomena that we call mental. New sensations, new emotions appear as development proceeds to higher grades. Ideas arise. The inner life becomes highly diversified. In its later grades it contains much that was not present at earlier periods. Does development then produce what is really new? Is life indeed upon a new adventure?

Into this particular question we must now inquire with care. And first we must ask: What of the beginning of life?

Did life always exist? Or was there a time when there was no life; so that life must have begun at a certain time? Did life come into the universe as something new?

Our usual practice implies that it did. We are ac- 
customed in biology to distinguish between living things and material that is not living. A man, a dog, a plant, a bacterium-these are living. But a stone, a gas, a mass of molten iron, a burning vapor-these, according to our usual judgment, are not living. It is true that there exist also certain things about which we may be in doubt as to whether they should be considered living or not living. Such are enzymes, such are filtrable viruses. But as between marked cases, as between a man and a stone, as between a bird and a mass of molten iron, there is, in our usual way of viewing these matters, no doubt; one is living, the other is not. We are accustomed, too, to see the living transformed by certain conditions into the non-living. On this basis, we are accustomed, as a result of observation and experiment, to distinguish conditions in which life may occur from conditions that are incompatible with life. We find and report in our scientific papers that there are many conditions under which life cannot exist. Indeed, we find and report that life does occur only under a narrow range of conditions. You may find the conditions which limit the occurrence of life enumerated in any textbook of physiology. Among the conditions which are experimentally incompatible with life are high and low temperatures, certain chemical conditions, and a large class of physical conditions. If we subject living things to these conditions, all the characteristic phenomena of life, including the mental phenomena, disappear, and we say that our material is no longer living.

Are these statements correct? Does our distinction 
between what is living and what is not living mean anything? Has our enumeration of conditions under which life can occur any significance? If so, if these statements and distinctions are valid, this fact is of vast import for our understanding of the nature of the world and the world process.

For we discover that there was a time in the history of our solar system when the physical conditions were such that life could not exist. This has indeed been the history not only of the solar system, but of all parts of the universe. There was an early period in which the physical and chemical conditions were of the kind in which life does not occur. If we now experiment with such conditions, we find that they destroy life. Both the outer phenomena and the inner experiences of life disappear under the conditions that prevailed at earlier epochs.

If the distinctions that we make in our books of physiology between the living and the non-living are valid, then life did not exist in those early periods. Later, life appeared. Therefore it came into existence at a particular time, when the conditions and combinations occurred that permit and give origin to life.

I believe that we shall do best to hold that our usual distinctions between the living and the non-living are indeed sound and valid. We find them a necessity in practice; without them, biological science becomes nonsense. Assuming this distinction to be sound, we must hold that, at an early period, life did not exist. At first without life, the universe later produced it, including both its outer aspects and its inner experi- 
ences. At a certain time, life came into a lifeless world. At a certain time sensation, emotion, came into a world that was without them.

The only alternative to this is to hold that there is no distinction of living and non-living; to hold that the statements in our scientific writings on this and on the conditions necessary for life are meaningless and incorrect; to hold that stones and molten or gaseous metals are living; to hold that atoms and electrons and protons and neutrons are in some sense living. But even if we take this alternative, we do not escape from the production of what is new as time passes. The elemental life of electrons and atoms, if there is such life, is clearly of a different type from the organic life of plants, animals, men. No one can hold that an electron or an atom has sensations of red or blue, feelings of nausea, emotions of hope or fear, ideas or purposes. Such hypothetical elemental life does not include the phenomena that are characteristic of life in its higher reaches. These phenomena that are typical of higher life did not at a certain time exist or occur. They came into existence only as certain combinations of the materials of the universe were made. The situation remains therefore in principle the same, whether we do or do not attribute life to molten metals and to atoms and electrons. In either case phenomena characteristic of the higher reaches of life at first did not exist and have later come into existence.

Thus new things appear in the universe as time passes and conditions change, new things of the very 
greatest interest: a fact of capital importance. But for its full significance, we must make certain other inquiries concerning the appearance of life. Is the later appearance of life, including its inner and outer phenomena, a mere logical or computational outcome of the conditions that preceded it, as the operation of a machine is a consequence of the way the machine is formed? Science, says Conan Doyle, has made the universe "a mere clockwork mechanical wonder swinging in a vast vacuum." Is this true of biological science? The operation of the machine can be computed and predicted beforehand from a knowledge of its structure. Is this true of the appearance of life? Is the development of life the mere operation of a machine, computable and predictable, from knowledge of the machine before life appeared?

Put more precisely, the question is as follows: The materials of the solar or stellar systems at certain early periods included none of the phenomena of life; certainly none of the phenomena characteristic of the higher forms of life. But what has happened since shows that these materials were indeed such as could and did give rise to the outer and inner phenomena of life, after certain changes and recombinations had occurred. Our question is: From the existence and properties of the fiery mist of those early periods, could the later appearance of life be predicted by means of reasoning and computation? Or, in the appearance and development of life, has something fundamentally new appeared; something that could 
be known only by experiencing it? The answer to this question will be decisive for much of our attitude toward the world.

Considering science as the formulating of experience, this question must be put as follows: Would experience that was limited to the fiery mist as it occurred in the early epochs make possible the prediction of the outer and inner phenomena of life, its activities and its sensations, emotions, mental experiences? Confronted with samples of that material, perceiving the particles of which it was composed, their velocities, directions of motion, and distribution in space, could the investigator hope, by logic and the aid of an unlimited computing machine, to compute from its properties and distribution the later emergence of life, including varied sensations, feelings, ideas, and thoughts as they have later come forth?

This question can be answered only No! From computations that begin with particles, velocities, directions, distributions, there can emerge by computational and logical treatment only particles, velocities, directions, distributions-never a sensation. A sensation of red does not logically or computationally follow from an arrangement of particles in combination with vibrations of a certain wave length. Not the hardiest mechanist has attempted so to derive it. The approved procedure is to "abstract from" sensations and other inner experiences, to ignore them, to say that science does not deal with them. The utmost that can be done is to discover by experience that the sensation of red 
does, in fact, occur when there are certain combinations of particles and vibrations; and to use that experienced fact, so discovered, in later predictions.

And what is true for red is true for other sensations and feelings; for mental experiences in general. Each type is discovered by direct experience. None is originally discoverable by computation or reasoning from antecedently existing arrangements, velocities and directions of particles, and wave lengths of vibrations. All come into existence as certain combinations of the physical constituents of the universe are formed.

We have here one of the great fundamentals that is discovered by the examination of biological material. The universe is not given complete, once for all. As time passes and conditions change, new, logically ultimate things come into existence; things that are discovered only by experiencing them, and that could not be predicted from what has gone before. ${ }^{1}$ Development, as it occurs, includes the production of what is in a real sense new. Sensations, emotions,

1 Well-known works dealing with the view that new and ultimate phenomena arise in the process of evolution are: H. Bergson, Creative Evolution (New York, 1911); C. Lloyd Morgan, Emergent Evolution (New York, 1926) and Life, Mind and Spirit (London, 1926); A. O. Lovejoy, The Discontinuities of Evolution, in the "University of California Publications in Philosophy," V, 173-220; W. E. Ritter, The Unity of the Organism, or the Organismal Conception of Life (Boston, 1919). A worth-while critical discussion of such doctrines is found in William McDougall's Modern Materialism and Emergent Evolution (New York, 1929). The subject was discussed by the present author in the last chapter of his book The Biological Basis of Human Nature (New York, 1930). 


\section{Nature of the Universe}

knowledge, purposes, ideas, ideals, were earlier not existent; later they exist. At first without life, the universe produces it, including its outer aspects and its inner experiences. In other words, the lifeless universe comes to life; at first dead and inert, it begins to become conscious of itself, it begins to feel, to think, to have ideas and purposes and ideals. This constitutes one of the main features of the biological picture of the universe.

Next we must inquire into the consequences of this coming to life and consciousness. Is the production of what is new limited to the things of the inner experience? Or do these things, when they appear, alter the movements, the chemical and physical processes that occur? If they do, then physical and chemical changes occur in a different way after the appearance of sensations, feelings, purposes; there is development in the laws of movement as there is in things mental. If they do, then mental things are important factors in the progress of the universe. Are these things true? To these questions we turn in our next lecture. 

THE NATURE OF THE UNIVERSE AS REVEALED BY THE STUDY OF BIOLOGY [Continued]. PRODUCTION OF NEW METHODS OF ACTION AS WELL AS OF NEW MENTAL PHENOMENA. NATURE OF EVOLUTIONARY PROGRESS.

T $\mathrm{N}$ our first lecture we concluded that, in view of the 1 facts of biology, the universe is not "a mere clockwork mechanical wonder swinging in a vast vacuum," but is a system that, in the course of time, comes to life. It begins to feel, to suffer, to enjoy, to be aware of itself, to have ideas and plans. It develops. Its course in development is not stereotyped, not mechanically and mathematically predictable. In giving rise to mental phenomena, the universe produces things that are new and ultimate, only known as they occur and are experienced.

And now another question that is of fundamental significance for our picture of the universe, for our understanding of the nature of reality: Do these new things make any difference to the course of events, to the physical and chemical changes that occur, to the movements that take place? Or are the feelings, ideas, plans, purposes, when they come into existence, completely idle so far as the rest of the universe is concerned? Is the production of what is new limited to mental phenomena, everything else continuing as be- 
fore? Or do sensations, feelings, purposes, and the like, affect motions, behavior, arrangements of materials, structure? If they do, then physical and chemical changes, motions, occur in a different way after the appearance of mental phenomena. If they do, then as time passes there is development in the laws of motion; new laws of motion appear in later periods of time; laws of motion that could not be known or predicted from what happens in earlier periods. If this is the case, then the course of events in later periods could not be computed from a knowledge of the conditions in earlier periods. The behavior of men, of yourself and myself, then could not be computed and predicted from conditions occurring before man existed-as some have suggested doing - because the data for such a computation did not exist at that early period. Is this really the case? Do new laws of motion indeed occur as mental phenomena come into existence? Do sensations, feelings, and purposes make a difference to the events that occur?

There is a doctrine that is widely held, under the name of mechanism-a doctrine that is inclined to present itself as the only legitimate offspring of science-which assumes that new laws of motion do not appear as time passes and new combinations occur. Mechanism assumes that the laws of motion exemplified in the movements of the elementary particles in the earliest periods of time are the only laws of motion, and are the same laws that result in and express all movements that occur in later periods, including the movements of animals and men. Thus 
from data existing at the earliest periods it would be in principle possible to compute your behavior, my behavior, the behavior of all men, the entire course of human history. Sensations, emotions, desires, purposes, and knowledge would not come into this computation, so that when these things come into existence, from this point of view, they do not influence the movements that occur; for these movements could be computed without taking them into consideration. The same physical conditions, without the mental states, this theory holds, would produce the same behavior. The fact that I am hungry (that is, that I have sensations of hunger) has nothing to do with the fact that I eat; in general, the fact that hunger occurs in the universe has nothing to do with the fact that eating occurs in the universe. The fact that I have some knowledge of biology has nothing to do with the fact that I give lectures on that subject; I would give exactly the same lectures if I had no such knowledge. The opinions that I hold, the thinking I have done, have nothing to do with what I am saying to you. Such is the thoroughgoing doctrine of mechanism.

Is this doctrine sound? Must we hold that feelings and ideas and knowledge and purposes have no function in the world; that they make no difference to what happens? No question can be more important for our outlook on the world. We shall therefore examine in some detail this question, of the validity of this widely accepted doctrine of mechanism.

Argumentation in support of this doctrine has 
taken various forms. One line of argument is of a strictly a priori character, not based upon experience or experimentation. There can be no functional relations, no relations of cause and effect, it urges, between things that are so totally different in kind as are motions and emotions, as are particles and sensations, as are actions and thought. A wish, an idea, cannot produce or change a motion, it is held, because a wish or an idea is in its very essence a different kind of a thing from a motion. And for the same reason, a motion, a rise in temperature, any physical change, cannot alter sensations, ideas, wishes.

But such an argument mistakes the nature of scientific knowledge. Science is man's attempt to organize his experiences, to formulate observed relations. It is compelled to deal with many things that are ultimate; things that are to be learned only by experiencing them. Its final foundation is critical observation and experimentation. To these it must be loyal to the end, if it is indeed to present itself as a formulation of experience. If it abandons them, it is lost; it then becomes merely one more system of metaphysics.

And critical observation and experimentation show that mental states and physical conditions are not independent. Heat and cold yield different sensations. Cutting the flesh with a knife yields very different sensations, emotions, and purposes from those that occur when this physical change does not take place. The physical objects that are present in a room determine what we see, determine what sensations our eyes receive. No matter how refined the 
technique and how critical the experimentation, physical changes are found to give rise to changes in sensations, emotions, desires, purposes, thoughts. A formulation of experience that ignored or denied these observational and experimental relations would be a mere caricature, worthless as a guide to action and ridiculous as a pretender to enlightenment. Our inner experiences are not independent of outer occurrences.

This disposes, for science, of the $a$ priori argument that there can be no functional interrelations between these two classes of things. Experimentally, observationally, there are functional relations; and science is but a formulation of relations discovered by observation and experiment. As investigation progresses, it becomes more and more clear that to each type of sensation or emotion or other inner experience there corresponds functionally some type of physical condition. When the typical physical condition is altered, the mental experience is likewise altered.

But how then about the converse relation? Do sensations, emotions, purposes, thoughts, knowledge, and the like, affect motion, physical conditions, behavior? Is it true that knowledge is power? Is intelligence indeed a guide to action? Or have these things nothing to do with our actions?

The $a$ priori argument that one of these sets of things cannot affect the other, we have already seen to be overthrown by the formulation of experience. The experimentally demonstrated fact that physical 
changes bring about mental changes shows that the physical and mental are not independent. The physical does affect the mental. But is it also true that the mental affects the physical; that thoughts and purposes and knowledge affect behavior? Or is there reason to suppose that the relation is all in one direction; that physical things affect mental experiences, but mental experiences do not affect physical things?

This is for science exclusively a question for experience and experimentation. Every day experience and laboratory experimentation agree in showing that different actions do occur, following upon different sensations, emotions, and opinions. If I purpose to eat my dinner, my action is different from that which follows upon a purpose to write a letter. If, in my opinion, Hoover was a better man for President than Roosevelt, my vote was different from what it would have been if I had held the reverse opinion. If spinach has a disagreeable taste to me, I decline to eat it. No one doubts that action is in fact different, following upon diverse mental states, different sensations, feelings, purposes, opinions.

The direct natural conclusion from this is the one that is drawn in everyday life, namely, that these things do affect action. The natural man supposes that different sensations, different purposes, different opinions, result in different actions; that a change of purpose or of opinion brings about a change of action. He supposes that a man of knowledge has, through his knowledge, an advantage in action over an ignorant man. He supposes that a sensation of 
pain causes one to withdraw from and avoid that which produces the pain, while a sensation of pleasure or comfort has the reverse effect.

But somewhat to the astonishment of the natural man, the devotee of mechanism as a philosophy rejects these conclusions. He holds that sensations, emotions, thoughts, purposes, and opinions have nothing to do with action. He holds, as we have before remarked, that sensations of hunger and thirst have nothing to do with eating and drinking. Sensations of cold do not influence our approach to the fire. Our political sympathies and beliefs have nothing to do with the way we vote. My thoughts and opinions have nothing to do with what I say to you in these lectures.

How does the mechanist escape from the natural conclusion that sensations, purposes, and opinions influence our actions? He believes that he finds an escape in certain relations between the physical and the mental that we have already mentioned. When different sensations, emotions, thoughts, and purposes are present, there are characteristic different physico-chemical conditions as well. When a sensation arises or changes, the physical condition of the organism changes also; when any mental condition alters, there is likewise an alteration in the physical condition. I am physiologically different when I am hungry, as compared with my condition when I am filled. I am physically different when I think, as compared with my condition when I do not think. When an idea occurs to me, my body changes within. 
Now, it is to this changed physical condition, not to the changed sensation or other mental experience, that the mechanist attributes the change in action. When the hand is withdrawn from a flame, the withdrawal is held to be due to the physical change induced in the hand by the flame, to the cooking of the skin, as it were, not to the sensation of heat or of pain. The same type of explanation is to be employed, it is held, in all cases of apparent influence of mental condition on action. When one weeps on receiving news of the death of a friend, this is not the result of emotion but of some physical change in one's body, resulting from the impact of the vibrations of which the words embodying the news consist. When one changes his vote after reading an economic discussion, this is not due to increased knowledge or to change of opinion but only to some physical consequence of reading the discussion.

Such a view is so contrary to all the experience and prejudices and practices of the natural man that he is inclined to believe that it must be correct; otherwise, no one would maintain such an apparent absurdity. A preposterous opinion carries a certain weight just because it is preposterous, for why should anyone hold such a notion except because it is correct? But we must not allow ourselves to be imposed upon by the mere apparent absurdity of a doctrine. How shall we find out whether this opinion of the mechanist is correct, as opposed to that of the natural man? How shall we find out whether to attribute the child's withdrawing his hand from the flame to the 
Nature of Evolutionary Progress 41 pain or to the physical alteration in his finger induced by the heat? How shall we find out whether my change of vote is due to my change of opinion or only to some physical change in my body?

The case for the mechanist would be proved if it could actually be shown that from a knowledge of the movements and distribution of particles at some period before life appeared, my behavior, the behavior of all animals and men, the course of history, could be correctly computed and predicted without taking into account sensations, emotions, opinions, knowledge. But no one claims that this has been done, or ever will be done, or indeed that, in fact, it can be done. The idea merely is that it would be possible if there were a sufficient knowledge of the distribution and movement of the particles at some early period, provided one were a sufficiently competent computer. But this is a mere supposition, totally unfulfilled; a mere speculation. It forms no foundation for the acceptance of a positive doctrine or for the dogmatic teaching of that doctrine. As Bergson has well said, the doctrine of mechanism involves the sacrifice of experience to the requirements of a system. The motivation of the doctrine is indeed a practical onethe desire to simplify the task of science. The universe would be so much easier to deal with if the laws of its action were simple and uniform. Let us assume therefore that they are simple and uniform! The doctrine is a marked case of wishful thinking.

The notion that actions are not influenced by sensations and other mental experiences; in other words, 
the doctrine that the laws of action are unchanged in the complex arrangements of matter which give mental phenomena, is not supported by experimental evidence, as I shall try to show; on the contrary, it is directly opposed to experimental evidence. Pearson long ago in his Grammar of Science ${ }^{1}$ emphasized that ground does not exist for teaching dogmatically that the laws of motion are the same in all combinations. The situation has been analyzed from a similar point of view by Lovejoy ${ }^{2}$ and doubtless by others. There is nothing in these speculations of mechanism that must drive us to reject the efficiency of mental states and events as determiners of action.

Such being the case, we must turn to other ways of answering such questions. The scientific way of determining to what condition an event is due is to separate the conditions under which the event occurs and to try each condition separately, so far as possible, until we find the one or ones that are essential for the event to occur. This is what is called analytical experimentation. It is the method of science, so far as the discovery of causes, of determining factors, is concerned.

Now, the actions of men and other organisms occur under certain conditions, and we wish to discover which of these conditions bring about the actions. A child burns his finger and withdraws it from the flames, or I change my vote after changing my

1 See Pearson, Grammar of Science (1895), chap. viii, "Laws of Motion."

2 See A. O. Lovejoy, "The Meaning of Vitalism," Science, XXXIII (April 21, 1911), 612. 
opinion. The preceding conditions include a certain mental state and a certain physical condition; that is, a condition perceived by the "inner" view, and one perceived by the "outer" view. We wish to determine to which of these conditions the action is due. We wish to know whether withdrawing the hand from the flame is due to the high temperature and accompanying physical changes in the hand or to the pain that occurs.

To answer this question, we must separate the two things. We must separate the physical condition from the sensation that occurs with it, and so find out whether it is really true, as the mechanist holds, that the same physical condition without the sensation would produce the same result, would, in this case, produce the withdrawal of the hand. And to discover, on the other side, whether the sensation is the exclusive agent, one must isolate it from its physical accompaniment and try it alone.

But these experiments have but to be proposed in order to reveal that they are impossibilities. When a certain sensation, emotion, or other mental state occurs, there is also a certain characteristic physical condition of the organism which is different from the physical condition existing when this sensation or emotion does not occur. To every difference in mental state corresponds a difference in physical state. One cannot remove the sensation or emotion and leave the physical condition as it was. And one cannot change the characteristic physical situation without altering the sensation or emotion. The particular sensation or 
emotion and its characteristic physical condition are always together; they are in effect one. And this is true for all mental states and their corresponding physical conditions.

This experimental inseparability, this oneness, of the given mental state and its characteristic accompanying physical condition, is the decisive point for the answer to our question as to whether it is the mental state or the physical state that causes the action; whether the way I vote is due to my opinion of the candidates or to my physical condition while I hold this opinion. Since the particular mental state-the opinion or purpose or sensation-cannot be separated from the particular physical state, ${ }^{1}$ but is, so far as experimentation goes, one with it, there is no possible experimental ground for asserting that one of these two things brings about the action to the exclusion of the other. And this means that there is no scientific ground for such an assertion. It cannot be asserted

1 It is sometimes pointed out, as if it were inconsistent with the principle stated in the text, that the same gross final result that is produced by an action which is preceded by a purpose or other mental state may in other cases be produced without a purpose. I may of purpose remove a picture from the wall; or a gust of wind may likewise remove the picture from the wall. It is, of course, a well-known principle that a given final result may be produced in many different ways. But to conclude from this that the purpose plays no part in the cases where it is present is as futile and unjustified as to conclude that the gust of wind plays no part in the cases where it is present. The only test in either case is to remove the suspected factor, leaving all other conditions the same, and thus to discover whether that factor plays a rôle.

Again, one may of set purpose strike a particular note on the piano, and later, after long practice, one may, in the course of playing a composition that one has learned by heart, strike the same note without the set purpose directed upon that particular note. From 
that the same physical condition without the sensation or opinion or other mental state would produce the same result, for the same physical condition never occurs without the mental state. And it cannot be asserted that the mental state alone is the cause of the action, for the mental state does not occur alone. The two stand on exactly the same footing experimentally and in science; if one is a cause of action, so is the other. The mental state and its characteristic physical condition are inseparable; experimentally and practically they are identified. We may, without practical or experimental error follow the example of those that call them two aspects of the same situation, ${ }^{1}$ the same situation viewed in two different ways. It is this situation that is the cause of the action. In speaking of this cause, we may call it by either of its two aspects, and one is as correct as the other. For experimental science, the mental state is the cause of action on the same basis as is the correlative physical condition, for the two are one. My opinion is the cause

this it is sometimes argued that the purpose when it did occur played no rôle. But this conclusion is experimentally fallacious as was the one before mentioned. For in all such comparisons, as in all cases where the same final result is produced in different ways, we have the following conditions:

(1) The antecedent physical condition differs in the two cases, that is, when a purpose is present and when it is not.

(2) The action itself differs in details in the two cases. Therefore this gives no evidence that the same physical state that was in the first instance accompanied by a purpose would produce the same result when not accompanied by a purpose, for that same physical state does not occur without the purpose. These considerations apply to all arguments of this nature.

1 See, for example, H. C. Warren, "The Mental and the Physical," The Psychological Revier, XXI (1914). 
of my voting in a certain way; and so is also the physical condition that goes with that opinion, for the two are experimentally the same thing.

Thus in describing the causes of the actions of men or other organisms, we may use either the mental state or the physical condition, as is most convenient. In dealing with lower organisms or with simple reactions, it will be most convenient and most helpful to employ the physical condition. The student of physiology may properly attribute the withdrawal of the finger from the flame to the rise in temperature of the nerve endings in the skin, although he cannot properly deny that the accompanying pain has a rôle in the matter. For explanation of the behavior of man, particularly of his more complex actions, it will commonly carry more insight if one refers to the mental states. For explanation of why I voted for Hoover in place of Roosevelt or vice versa, or for explaining why I say what I do in these lectures, the statement in terms of physical conditions is extremely involved, uncertain, and unintelligible. So it is better in such cases to refer to thoughts and opinions and purposes as accounting for the actions. Both have the same degree of scientific justification, both are fully justified.

We conclude then that, for experimentation and therefore for science, mental states have effect on action. The ground for this assertion is of the same character as for the assertion that any other agency has effect on action. Sensations, emotions, ideas, pur- 
poses, opinions, and knowledge decide our conduct. Ideas and ideals are efficient agents in determining what happens. The laws of action, the laws of motion, we conclude, are different when specified mental states are present, as compared with the methods of action when those mental states are not present or when other mental states are present. This is one of the fundamental principles for our biological outlook on the world. It affects all our further conclusions.

One conclusion follows at once, a conclusion that is of the greatest import for our outlook on the world. Since sensations, emotions, ideas, and other mental states have come into existence in the passage of time, thereupon altering the movements that occur, it follows that the laws of movement are not given complete in the early epochs, but that new laws are exemplified as time passes and new conditions arise. As new combinations of the elementary constituents are formed, new methods of action come into operation.

What occurs now was therefore not predictable before life came into the world. My behavior, your behavior, the course of human history-these things were not in principle to be computed from the movements and distribution of the elementary particles in the early ages. What is to come in the future is not predictable from what is now present, for we do not know what will be the rules of action, the laws of motion, when other mental states shall have come into being, when there are other sensations, purposes, ideas. The universe produces new things; produces sensations, emotions, ideas, where none existed; pro- 


\section{The Universe AND LIFE}

duces new mental states as time passes. And with these it produces new methods of action. It is not true that the thing that has been is the thing which shall be, that the thing that has been done is the thing that shall be done, and there is no new thing under the sun. On the contrary, new things and new methods of action come forth in the process that we call evolution. $^{1}$

It will be observed that this situation makes no difficulties for the practice and formulation of science, if science be considered an observational and experimental matter. It is as things come into new relations that new phenomena and new methods of action appear. There is thus always an experimental cause for every diversity of result. There is no obstacle to the complete carrying through of the methods of experimental science, even of objective or purely physical experimental science, since distinctive physical conditions always coexist with different mental states. Experimental determinism holds throughout; and this is what is required for building a science that is a formulation of experience. It is a widespread error to suppose that the possibility of science rests upon the validity of the theory of mechanism. What the upbuilding of science depends on is merely the principle that what happens depends on the conditions, and that when different things happen, there are different preceding conditions. It does not demand that all the

1 For related discussions and conclusions, see references given in the note on p. 30 . 
laws of action shall be exemplified at any particular moment. When new conditions arise, new laws of action are exemplified; but they are to be formulated in terms of the conditions just as were the old laws. And all the old laws remain in effect so far as the conditions they specify continue to prevail; the new laws are merely added to them as they are discovered.

Biological science lends no support to the doctrines of indeterminism that have become rife in certain branches of physical science. The organization of science is made possible by the prevalence of experimental determinism. Experimental determinism consists in the observed fact that later perceptual diversities between two sets of phenomena are preceded by earlier perceptual diversities, so that if the earlier diversities are removed by experiment the later ones likewise disappear. The farther investigation is pushed in things biological, the more complete becomes the prevalence of such determinism. The history of biological science is one of steady progress in the discovery of experimental determiners for biological happenings. It leads by induction to the conclusion that there is no bar to the extension of this kind of knowledge to any case whatever; in other words, to the conclusion that experimental determinism holds throughout all things, and that any diversity of results is preceded by a diversity of conditions. But this does not mean that all action is stereotyped and predictable. It does not imply that a given individual's actions are predestined, fixed by conditions that existed before he came into being; 
it does not mean that his individuality counts for nothing in the course of events. On the contrary, as new combinations of the constituents of the universe are made, new phenomena and new methods of action occur. Among these new phenomena is the particular individual, with his special combination of desires, hopes, fears, purposes, ideas. These help to determine what occurs.

This is the just basis for the conception of freedom of action. The individual is not controlled exclusively by forces lying outside of himself, forces extraneous to his own individuality. His conduct is not governed by rules of action that were discoverable before his existence. $\mathrm{He}$ is a new combination with methods of action that are not determined by what occurs in other combinations. His freedom is thoroughly compatible with that experimental determinism on which depends the practice of life and of science; but he is determined by conditions that did not before occur, by conditions that lie in his own individuality.

This biological outlook is thus thoroughly compatible with the practice and formulation of science. But since the universe changes with the passage of time, yielding new phenomena and new methods of action, science can never be finished. It must continue to develop, to change, to progress, as long as evolution continues. In this, it partakes of the nature of history; its later content is bound to be different from its earlier content, since the universe itself is different. As new things appear, science must be so modified or supplemented as to give an account of 
them. Yet nothing in the later science is in contradiction to what was in the earlier science, provided science sticks throughout to observation and experiment. For the phenomena and laws of action discovered in later periods have arisen from conditions that did not occur in the earlier periods. In describing and explaining them, it is these new conditions that must be taken into consideration. The methods of action of the living creatures do not oppose or contradict those of inorganic bodies; they are merely other methods, additional methods, that are to be incorporated into science on the same basis as the laws of inorganic things.

Return now to what occurs in the development of life. It is clear that the production of phenomena that are new is not limited to the first appearance of life. The simplest organisms - the filtrable viruses or bacteria or amoeba-like creatures-obviously did not and do not experience the sensations, emotions, ideas, and mental states in general, with their correlated methods of action, that occur in the higher animals and man. And the later mental experiences, such as are found in man, are not predictable from such as occur in the simplest forms of life. Organic evolution thus involves repeated or rather continual production of phenomena and ways of action that did not before occur and were not predictable from what did before occur. The universe did not become sterile with the first production of life. It is continuously creative now as in the past. 
Most momentous is another characteristic of life and development. As the universe comes to life, as it begins to feel and to think and to know, this does not occur uniformly throughout all its parts as one great unity. It occurs only in definite localized centers. And life does not occur and develop as a single unified phenomenon, as one continuous organism. On the contrary, we find life now occurring and developing in a great number of diverse centers separated in space. These separated centers we call individuals; myself, yourself, our friends, my dog, the sparrow I saw in the tree as I walked in the park. Each one of these individuals is an integrated group of structures, activities, and inner experiences. Each has sensations, emotions, and mental experiences that are separate from those of the other individuals. And in each individual all these things develop from a simple condition to a complex, highly diversified condition, so that to each taken separately there applies what we have already said as to the nature of development. Each, too, is a center of experience, a spectator of the world as well as an actor in it; a center which retains its separate identity, its "personality" among the changes that occur. This is a matter to which we shall return; now we look particularly at certain other peculiarities of these individuals.

The separate centers of life and development-the different individuals - are not duplicates. On the contrary they differ greatly among themselves. There now exist diverse types among them-bacilli, amoebae, snails, dogs, men. But many of these diverse types 
were originally one; they had a common origin. Whether all existing organisms had thus a common origin is doubtful. But from the uniformities seen in the fine structure of their cells and chromosomes, it seems clear that the animals, along with perhaps the higher plants, all came from a single center. They were once a single mass, simple in character, perhaps somewhat like the protoplasm of an amoeba. This original great organism has become separated into many pieces, of which each of us is one. The dog that follows me on the street, the bird to whose song I listen, the mosquito that I try to drive from my face, the infusorian that I see under the microscope-these, like myself and yourself, are pieces of that original organic mass. We are all in that real sense brothers; we are in literal truth children of the same original parent; we are all one flesh; we are pieces of the same original organic material. A constant realization of that fact is the clue that must guide us in our interpretation of the world of life. With St. Francis, we must realize always that the birds and beasts are our brothers.

These pieces, these brothers, which were originally one, and thus were all creatures of the same kind, have since developed in many different directions until there have been produced the great number of diverse types that exist now : insects, crustacea, birds, men, and thousands of others.

Thus the progressive changes that are one of the great characteristics of life do not occur in a single direction but in many directions. There is a copious 
and multifarious diversity in the tendencies to change, in the production of new forms, new types. Evolution is indeed, as Boas ${ }^{1}$ suggested, "creative and fanciful, exulting in diversity." Like the famous warrior of the enthusiastic chronicler, life "leaps upon its steed and rides furiously in all directions." The paths of divergent evolution branch like a growing tree, with changes of different kinds occurring at the end of every twig.

And now an unwelcome fact about these lines of development but one that is verifiable - a fact that is important for our picture of life. The directions in which changes move include many blind alleys, many paths in which continued progression is not possible. After a move in such an impracticable direction, the branch dies and disappears. A new lasting type is not produced. To make mistakes is one of the characteristic phenomena of biology. If we personify life, we must say that it delights in experimentation; it is a pertinacious and undiscouraged experimenter. And many of the things that it tries are of the sort that Darwin called in his own work "fool experiments" with scarcely a chance of success. It will "try anything once." In fact, it will repeat the same unsuccessful experiment, the same tragic mistake, a hundred times. Having produced an efficient creature with wings and legs and muscles and nervous system that work in beautiful coördination and with many excellent sense organs to guide it-a creature that

1 George Boas, The Adventures of Human Thought (New York, 1929), p. 391. 
steers successfully its course through this difficult world-life tries dropping out or damaging or altering at hazard one part after another. This is a process that has been studied on a vast scale in certain organisms; notably in the famous fruit fly on which, in such large degree, our knowledge of heredity and variation is based. Life produces types that have no eyes, and that therefore have no chance for continued existence. It produces types that have no wings or have wings that are useless for flying; types with too many legs that get in each other's way; types with imperfect sense organs; types that are monstrous, types that are weak, types whose parts are uncoordinated in their action; types that carry within themselves the seeds of their own destruction. In hundreds of ways, life produces imperfect types, many that cannot continue to exist even under the best of conditions; many others that, under most favorable conditions, weakly carry on for a few generations but die under the first change of fortune. These are not matters of theory; hundreds of such imperfect and inefficient types, even in single species, have been studied in detail, described in full, their origin and fortune and fate followed with thoroughness. ${ }^{1}$ Indeed, when one studies minutely and in detail for generation after generation the reproduction of any organism, including in his view large numbers of

1 For descriptions of great numbers of these imperfect types in a particular organism, see Morgan, Bridges and Sturtevant, The Genetics of Drosophila, particularly the list of mutant types at the end. See also, for full details, the papers referred to in the bibliography of the above work. 
individuals, nothing is more striking than the great numbers of imperfect, unadapted individuals that are produced. Whether we study thus the infusorian, the fruit fly, or man, we find produced misshapen creatures, weak creatures, individuals that lack essential organs, individuals whose senses are imperfect or who lack certain sense organs; individuals whose internal organs work but ill, whose intimate chemical processes are imperfect; individuals whose nervous systems fail to provide guidance. And the imperfections, it is found, are in the essential constitution of the creatures, for in so far as they reproduce, they bring forth anew imperfect offspring like themselves. Types that are weak, imperfect, incapable of continued life are started with the same profusion as are the efficient, adapted types; in fact, in a hundred times greater profusion. Students of genetics find that most of the new races begun by mutations in the hereditary constitution are of these imperfect types. Such defective, unadaptive types soon die out, some without reproducing at all and leaving no record; others after a few generations. Some persist for a time, to found a weak type or species that eventually disappears. The pathway of developing life is profusely marked with these imperfect starts, with the attempts of life to move in directions that lead but to conditions in which life is impossible. This is something that is not to be forgotten in any interpretation of life; we shall return to it.

But in other directions, in many branches of the life tree, growth and progress can continue and 
do continue. The changes in many of these branches are of a sort that can be called progressive. They lead to a fuller, more varied, more differentiated life. The original organic mass was amoeba-like, without organs of sense; without differentiated organs of any kind, to bring about a correspondence between its activities and those of the surrounding world. In many of the groups of organisms that have branched forth from this original condition, organs of various sorts arise. Sense organs of different types come into being, giving fuller correlation of the inner life with the outer processes. Many other structures arise which have similar effects. The inner processes-the mental experiences and their correlated behavior-become more and more complex, more diverse in kind, more responsive to the different aspects of outside nature. It is very clear that the life of man is fuller, more copiously and adequately correlated with the rest of the processes of nature, richer in its diverse mental experiences, than is the life of a bacterium or an amoeba. There are in the organic world many great series of such degrees of fulness of life and adequacy of correlation with the rest of nature-series leading in many different directions. The existing groups of organisms-infusoria, snails, flies, sparrows, mice, cats, men, and hundreds of others-illustrate and exemplify the multifarious results of progression in many different directions. They are the stations which advancing life has reached up to the present time. Some, it is clear, have reached degrees of fulness of life and adequacy 
of correlation with the outer world that are far beyond the degrees reached by others. For brevity, we will call such fuller, more diversified, more adequate life higher.

These developmental changes in many different directions are still in progress. Life is transforming now as it has transformed in the past. This is no longer a theory; the processes of transformation are now under observation in hundreds of laboratories of genetics. And life is bound to continue this transformation in the future. The universe is not finished, it is still in the making; and what it will produce in the future, we cannot predict. As it was not possible from what existed in the past to foretell the present situation of life, so from the present situation it is not possible to know what will come in the future. It is not possible to set limits to the further progress of life. If stock had been taken in some past geological age, much that is most characteristic of life would have been omitted; particularly, all that is now highest would have been left out of the reckoning. Stocktaking at the present time is bound in the same way to omit much that will be realized in the future. The potentialities of the universe for the production of diverse and higher types of life have not been exhausted.

There is possibility of progress toward fuller, more diversified life in any of the different branches of the tree, and in any of the multifarious directions in which life has successfully moved. In a book published some years ago entitled This Simian World, Clarence 
Day humorously proposed the question: What would be the situation of life and of civilization if other groups of animals had seized the advance guard of development instead of the higher apes and man? What would be the state of affairs if the cats or the elephants had been the first to develop a large, complex brain and had taken the lead and produced a civilization? Such questions touch real possibilities; they touch what might indeed have occurred in the past or might yet occur in the future. They are most suggestive; they are worthy of meditation. Supercats, super-elephants, equal to or beyond present mankind in mind and social organization are possibilities of evolution. From any of the groups of animals such superior creatures may or might arise.

It is true that on earth man has the very great advantage of now being in possession of the advance. He can head off and destroy any other type that tends to overtake or obstruct him, and everything indicates that he will do this in effective fashion. Evolution toward higher types, so far as the earth is concerned, is probably to be looked for, if at all, in man rather than in any other animal.

Yet if mankind fails, if through dissensions and wars, if through his own too great multiplication and through his inability to control the complex organization that he has produced, man at last destroys himself, as some now anticipate, it is to be remembered that the resources of the universe in the advancement of life are not thereby exhausted. Vast areas of the universe have not yet realized their po- 
tentialities for the production of life. If man disappears, if he turns out to be one of the numerous branches that is not capable of continued existence, and if none of the other existing types can seize the advance, still other innumerable types may well arise and start new cycles of evolution. Man is not indispensable to the advancement of life.

But if man succeeds in overcoming his present difficulties and continues to exist, we cannot suppose that he is at the end of his developmental career. As the development of life has progressed from amoebalike creatures to man, so it may advance from man to conditions of fulness and adequacy that are far beyond what man now represents. The idea of a superman, of many grades of superman, is not a mere mythical fancy but a possibility, or, rather, a probability. The time which lies before us is as great as that which lies behind us. It may do as much for the advancement of life. Whether the further development of man, if such occurs, will come chiefly in his intellectual faculties or in both these and his physical features, we cannot know. But the path of intellectual improvement lies open. Even to raise the average of mankind to the level of the highest that have already existed-to the level of a Goethe or a Leonardowould mean a tremendous advance. How far life may go in such an advance, we do not know.

And now we come to a question that underlies many religions: a question that is analogous to one we discussed in relation to mechanism. The question is essentially this: Is life upon a new adventure, climb- 
ing to heights not before reached; or is it the stereotyped unfolding of something before in existence? With relation to mechanism, we asked: Is the course that life follows the mere mechanical working out of a preëxisting machine, something predictable from knowledge of the structure of the machine? Here we ask a similar question from another point of view. Is life guided in its course by something that exists anterior to and outside of itself? Is there a goal of development that is already marked out? Is the path already laid out along which life is to advance? Or is life exploring a new way? Are the successive higher stages that life reaches in evolution indeed higher than what has before existed? Or are they mere approaches to an ultimate highest that already exists? Is what comes forth in evolution actually new, or is it the mere fulfilment of a pattern that exists beforehand, the mere approach to a condition that is already realized?

To these questions many reasoners have been disposed to answer that life is not upon a new adventure; that it is under guidance; that it tends toward a goal which is already existent; that the successive higher stages of life are but approaches to an ultimate condition which now exists and has existed since before evolution began. This ultimate that is held to guide the course of life, this highest state that existed before biological life began its progression and toward which life is again climbing, is given the name God. Does the study of biology, does the scientific study of life, lead to such a conception? A recently published 
book bears the title: Has Science Discovered God? ${ }^{1}$ What of biological science? Has biological science discovered God?

So far as I can see, it has not, if we give to the word God any such meaning as I have set forth. There appears to me nothing in biological science, nothing in general reasoning based upon the data of biology, that indicates that life is not upon a new adventure. So far as biological science can see, the highest stages that biological life has reached in its progress at any given time are indeed the highest stages that have yet been reached. So far as biological science can see, there is no indication of the previous existence of a prototype, a final goal, toward which life is tending; there is no evidence that life already exists perfect and complete before it begins its biological progress upward.

The progress of life is not of the kind that would be anticipated if life were following a certain existing pattern, seeking a goal already set or being guided by an all-knowing and all-powerful being. As we have before set forth, life moves into a million blind alleys. It attempts to exist and to operate with imperfect, inadequate organs, by imperfect, inadequate means. Most of its efforts fail. The progress that it makes is through the survival of a few successful remnants out of millions of failures that perish through their imperfection and inadequacy. The progress that life does make is not toward one goal but toward thou-

1 Has Science Discovered God? A Symposium of Modern Scientific Opinion, ed. E. H. Cotton. 
sands of diverse and incompatible goals. The progress of life in one direction destroys progress made in other directions. In a word, every indication that might be sought of a guidance of life toward a preexisting goal is lacking. All the indications are that life is indeed upon a new adventure, and that the highest conditions which biological life reaches in its progress upward are indeed the highest that have been reached. Whether that highest stage has been reached in the evolution that has occurred upon this particular planet or in that which has occurred upon some other planet, of course we cannot know. But there is no evidence that the stages of life reached in some other star influence the direction of progress here.

The conviction of the existence of God, in any such meaning as I have just indicated, has not arisen through the study of the detailed facts of science. In part, it is a reflection of wishes, the outgrowth of a desire for an all-wise, all-powerful protector and father. In the practice of science, the tendency to base convictions upon wishes is one of the chief errors to be avoided: it does not lead to verifiable truth; on the contrary, it leads to demonstrable errors. The reaching of conclusions through the influence of wishes is most strongly opposed to the spirit of science; and the conclusions so reached can lay no claim to support by science.

Aside from the influence of wishes, the favored argument for the existence of God, in the sense I have suggested, is the argument from contrivance. The 
existence of such complex, efficiently working arrangements as are found in the world, and particularly in living organisms, demands, we are told, the previous existence of a maker, a contriver. This contriver, since he plans and produces the contrivances, includes beforehand in some sense all that later appears in the contrivance; includes these and more. $\mathrm{He}$ includes them perhaps in concept, in thought; but the essence of the argument is that he does include them.

Thus the argument is that in order to account for the existence of the visible working contrivance, we must assume the previous existence of a still more perfect contrivance; one of the second degree, as it were. If the argument is valid, we must again assume a further contriver, one of the third degree, in order to account for the existence of this one of the second degree, which was assumed in order to account for the visible one of the first degree. But this leaves us just where we were: we must then assume a contriver of the fourth degree for the one of the third degree and so on ad infinitum. In other words, the argument from contrivance to contriver gets one nowhere; it leaves the origin of things just where it was. It is better to take the phenomena that are presented to us, dealing with these, formulating them as they are presented to us, rather than to embark upon a neverending recession of concepts of successive degrees of perfection one behind the other, which is the consistent outgrowth of the argument from contrivance.

What the course of evolution presents to us is essentially a picture of the method by which complex, 
efficiently operating beings, such as are found in living things, do indeed arise without a contriver, without a pattern or guide. The method, as we saw before, is to move in all directions, until some direction is found in which progress is possible. The method is to produce structures of every possible type, most of them so imperfect and inefficient that they disappear; but, among the rest, some that continue to exist, some that are efficient. These then serve as foundation from which another great set of experiments may be launched, most of them unsuccessful, as before, but a few successful. And so the process continues.

In the study of the progress of life, therefore, we find no reason to doubt that life is traveling a new course, the final goal of which does not now exist, the end of which is not now predictable. Life that is upon a new adventure, life that is moving in directions not laid out beforehand, life that is transforming into what did not before exist, life that is rising to heights not before reached-this is the vision that biology presents to our eyes. And this is a vision that is at least as interesting, as inspiring, as would be life without originality, treading dully a course marked out for it beforehand. 



\section{THE MANAGEMENT OF LIFE.}

$\mathbf{T}$ the lectures preceding this one we have seen that 1 the universe comes to life as time passes; life appears in a lifeless world. Life changes, develops; breaks into streams that diverge in all directions; some moving to destruction while others progress toward higher conditions. Look now at certain problems in the management of life; problems common to our own life and to that of other organisms. Here we come upon the immediate bearing of biological knowledge upon conduct.

The success of organisms-their survival and efficiency, the fulness of their lives-depends not alone on their structure and inner physiological processes; it depends in large measure on the way they behave. It depends on their maintaining proper relations with the rest of the world. Life is a complex set of orderly processes, enveloped in a world of conflicting, clashing conditions and agents. Many conditions, many processes, in this outer world of the non-living, work against life, are destructive to it. Others are necessary to life; they favor and promote the activities and the survival of the living creature. In consequence, to keep life in progress involves complex reactions. The organism must avoid, retreat from, certain conditions; it must seize and hold other conditions. Life thus involves selectivity in a high degree; selectivity 
in a complex and deceptive world. This is true for all organisms; for amoeba as for man.

Thus from the beginning life is a task, a problem to be solved, a course of action to be determined; it requires management. Successful living, in amoeba and in man, involves long trains of behavior, directed toward assuring conditions that are favorable and warding off those that are unfavorable. The penalty for making wrong choices, the penalty for inaccuracy and inadequacy in the reactions to the outer conditions, is destruction, with the cutting off of the line of advance represented by the individuals that fail. Such destruction through incorrect behavior occurs on a vast scale; perhaps a majority of the individuals that begin life are thus destroyed.

In those that succeed and thus continue to exist and to perpetuate their line of advance, the inner processes and structures come to be more complex and more and more completely and accurately correlated with what occurs outside; selectivity becomes more and more precise and efficient. As the organisms rise higher in the scale, the kinds of things to which they react become more numerous and the relations sought for more refined. At first they search in the main for food and flee in the main from immediately destructive agents. But almost at the very beginning there exist also special relations to their fellows, even in the infusorian there is mating and parenthood and still other relations with individuals of their own kind. In the higher animals, in man, the situation has become extremely complex, with almost an infinity of 
relations to which the individuals react in the way of selection or rejection.

All this is reflected in the inner experiences of the organisms; in sensations, emotions; at higher levels, in knowledge and thought. In connection with the reactions that tend to avoid destruction, that tend to preserve life, there arise special sensations and emotions: pain, fear of that which harms; pleasure, desire for that which benefits. There comes to be a love of life, a fear of death. These are universal and characteristic features in such living things as have reached a certain height of development. Animals cling strongly to the experiences of life. They resist strongly such influences as tend toward life's disintegration. There is a joy of living; a regret, a terror, at ceasing to live. These are among the ultimate facts; they are among the things that are known merely because they are discovered by experience. And they are fundamental things for our understanding of life and for our own attitudes toward the universe, because we are ourselves typical representatives of life. The inner or mental life of the organism comes to consist largely in determining what to do that will promote life, what to do that will add to its fulness, its variety, its adequacy, and its continuance; and conversely, in determining what to avoid, what to oppose, that will injure or destroy life.

These are the experiences that lie at the foundation of our concepts of values, our ideas of right and wrong, and other related notions that imply preference. That which promotes the fulness and adequacy 
of life is that which is valuable; and there is no other basis for the concept of value aside from its reference to life, no other basis for the notions of right and wrong. That which is to be done is the right; that which is not to be done is the wrong; and the decision as to how any act is to be classified lies in its relation to the promotion of life. Value, right and wrong, and related ideas, have validity and meaning only with relation to life. For physics taken independently of life these things have no meaning; in the universe before life developed they had no existence. Their final foundation lies in the experience of living beings.

To determine what is to be done, what not to be done; in other words, to determine right and wrong, is an insistent problem for all organisms; it is not something that begins in man. The daily, the hourly, occupation of most organisms-high or low-is the seeking of conditions that are favorable for life and the avoiding of conditions that are unfavorable. In doing this, decisions are continually required as to whether certain things are or are not to be done; that is, whether they are right or wrong. With all organisms, life is a continuous process of selecting one line of action and rejecting another, of determining whether certain actions are right or wrong. The life of the single-celled organism is such a continual process of trial, with pursuit or rejection; it has its dramatic crises as has the life of higher creatures.

Attempts have been made, in some artificial systems of thought, to divorce the ideas of what is right 
from the practical question of what is to be done; but such divorce leads to confusion in thought and action. To say that a thing is right but is not to be done, or is wrong but is to be done, is contradiction in essence; it means a loss of contact with the foundation on which such judgments rest.

The process of determining what is to be done (or the right) is accompanied in ourselves by poignant emotions and by painful thought and difficult decisions. Other animals are pieces of the same material with ourselves. There is then no reason to suppose that these inner experiences are lacking in them, although they must occur in diverse degrees of differentiation and intensity in different organisms.

To determine what is right and what wrong-to decide what is to be done, what not-is not a simple matter even for the single individual taken alone. It would not be a simple matter if the great living organism had never divided into parts, so that all life lay in a single individual. But relatively simple it would be. The task would be only to do those things which promote the life of that individual; and to avoid those things which injure or decrease his life. Even so, for a higher organism with its numerous differentiated parts and functions and its innumerable relations with the outer world, the task becomes complex and difficult. That which is beneficial and right for one of his functions may be harmful with respect to another. Hence arise difficulties, conflicts, 
uncertainties of judgment; cases in which the rightness of an action can be judged only from later experience of its ultimate consequences.

But the task of determining right and wrong is rendered ten thousand times more difficult by the fact that all life does not lie in a single individual, by the fact that the living material is divided into many individuals, and that these represent many different grades of development of life. One set of difficult problems arises from the existence of many individuals of similar grade of development, all with like claims upon life; the individuals who belong to the same species or race or tribe or family. Another set of problems arises from the fact of diversity of grades of development; from the fact that there are organisms of many different kinds, some representing higher grades of life than others.

Look first at the difficulties that arise through the fact that there exist many individuals of the same type; through such facts as that we ourselves, for example, have fellow men. Each individual has his own problems, his own insistent needs for keeping in progress his own life processes, for promoting his own life. These requirements may come into conflict in many ways with the similar efforts of other individuals. This greatly complicates the task of the individual. For individuals with little insight, appreciating only their immediate needs and blind to more distant consequences of their actions, it leads to direct conflict with others; to violence, to crime, to war. But 
conflict is by no means the only type of relation between individuals. Each individual finds himself tied in many ways to others. There is the need for mates; a need that exists even in the lowest grades of life; a need whose fulfillment adds, in higher organisms, more than any other, to the fulness and adequacy and variety of life. There are the relationships of parent and offspring, tying the generations together by powerful bonds. There are requirements of mutual aid and division of labor; requirements that largely determine the course of life in many organisms, such as the ants and the bees as well as in man. There are manifold social relationships. These relations to other individuals-relations not of conflict but of coöperation-take up a large share of the activities of life. Such relationships are found in all organisms, as we have seen, even in those that are low in the scale, even animals made up of but a single cell. Social relationships, playing a great rôle in life, are by no means peculiar to man.

All these relationships develop their correlative inner or mental experiences. There is love for the life of the fellow creature; for the mate, for the child, for the parent, for companions. There is a satisfaction in seeing their lives flourish; there is a desire to promote the life of one's fellows as well as of one's self. These are among the most intense and the most powerful of the motives to action.

And these things are natural developments, as natural as the impulse and desire to preserve and promote one's own life. They are ultimate experi- 
ences; realities that we know because we experience them, as we experience the satisfaction of food when we are hungry. They are constituent parts of life, whose reality and validity rest on nothing else than the experience of living things.

Through these relations, taken in connection with the gradual advance in mental grasp, the single individual comes to recognize that there exist other individuals to whom life is as desirable, as valuable as to himself. The mental experiences of these other individuals he does not directly share, but indirectly he can share them. All these individuals are pieces of the same living material with himself, of similar grade of development, with similar capabilities of experience. The individual who has reached an advanced grade of mental development comes to recognize that there is no discoverable reason why the promotion of life for one of these pieces of the living material should be given preference over that of the others. It is as desirable, as right, for the others to flourish as it is for him. He comes to recognize himself as but a member of a greater organism, of which there are many equal members with equal rights.

This intellectual recognition of equality in claims of many individuals, including one's self, comes to reinforce that instinctive love for the fellow creature and sympathy with him that have developed earlier. The whole is the birth of unselfishness and of the conception of justice to others as part of the province of right or of what is to be done. Throughout, it is the promotion of life, of its fulness and adequacy, that is 
the right; it is the degradation or destruction of life that is the wrong. But life includes not the individual alone; it includes his associates; it includes the other pieces of the same living material of which he is one piece; it includes the other units of the great organism of which he is one unit.

This development of a regard for the interest of others, of unselfishness and of a feeling for justice among different individuals is, we must repeat, a natural growth; it is as much a natural growth as the urge to eat or to protect one's self. It doubtless comes into being later than these. But the later products of evolution are as distinctly realities-are as "natural" - as are the earlier ones; are natural in the same sense as are the earlier ones; they have the same claims to recognition as have the earlier ones.

But the development of consideration and solicitude for the welfare of others does not prevail without obstacles and conflicts. There are powerful influences working against these things; influences working toward narrow selfishness. The center and source of all such influences lies in one of the strange and ultimate facts of biology. This is the fact of selfhood, of individual identity and continuity; the fact that each of us is himself and no other. Each of us, as a feeling, thinking person, is tied completely to one and to only one of the millions of pieces into which the great living organism is divided. Each of us can say that $m y$ whole possibility of experiencing the universe is bound up with that one unit, that one individual body and its fate, out of the millions that 
exist. The experiences of that one individual come to me directly without mediation; they are mine and no one else's. With the destruction of that one body, my experiences end; the universe, so far as I am concerned, goes out of existence. The experiences of other individuals come to me only indirectly and through the mediation of many processes. And these other individuals may disintegrate and disappear without putting an end to my experiences, to my universe.

This one individual, this one body and the experiences that go with it, is therefore myself in a sense that no other one is. This unique relation of one particular individual to my experiences, to me, tends to give that individual a more vivid reality, to me, to the self, than any other has. I may be even led to hold, as some philosophers have done, that I am the only individual that exists; that there are no others, and that there is nothing outside of myself; that $I$ am the universe. Most of us do not go so far as this. But we cannot help but realize more fully our own reality, our own pleasures and pains, needs and desires, purposes and thoughts, than those of anyone else.

In consequence, each tends to insist more strongly that his own needs and desires and purposes shall be fulfilled than those of anyone else. And this indeed has within limits its justification. Each of us knows his own needs and purposes better than does anyone else; and many of these can be fulfilled only by himself. I must satisfy my own detailed needs, for no one else can. If every individual became so unselfish as to 
attend to none of his own wants, mankind would quickly disappear.

But attention to one's own needs is not inconsistent with recognition of the needs and desires and purposes of others nor with helping to fulfil these. In man we find that most individuals do thus recognize the rights of others. Exceptional individuals indeed occur that totally disregard the needs of other individuals when these conflict with their own. But such totally selfish individuals are merely blind to many of the realities of the universe, to some of the most important realities. Their vision is limited to a small area and to a few of the elements of life. They are imperfect individuals without foresight. They lack perception and understanding of the relation of different individuals to each other; they neglect these relations, usually to their own undoing and to the undoing of others. The seeming opposition between self-interest and the interest of others is merely the opposition between certain very immediate needs and certain equally insistent but less immediate needs. It is like the opposition between satisfaction of present appetite for good food, and a later satisfaction of intellectual or artistic needs. Satisfactory relations between the self and the other units which make up the great living organism of humanity are as necessary for full and adequate life as are food and drink. And such relations can be attained only by realizing that fulness and adequacy of life are as desirable for others as for one's self.

What things are included in the "fulness and ade- 
quacy of life" that we wish to promote? What are the things that are of worth; the things that make life full and adequate?

To this no simple answer can be given. It is only experience, it is only living itself, that discovers what things in life are of value. What life, in direct experience, finds satisfactory, that is satisfactory; what life finds valuable, that is valuable. The worth while includes all those satisfactions and experiences of life that are discovered to be good, as food is discovered to be good by a hungry creature; and that do not yield later consequences of evil that overbalance the good. We are dealing here with things ultimate that cannot be defined except in terms of experience. On the main outlines of what is of worth there will be general agreement. Health, strength, the satisfaction of the natural appetites and instincts; varied and pleasurable activity, as in business and arts; knowledge and understanding of the world of nature and the world of man, as in science, history, literature and philosophy; companionship with our fellows, concordant and pleasurable interchange and intercommunication with them; mental power, initiative, originality, creative ability-all these things are included in what is found to be of worth. Whatever the living creature finds satisfactory in the long run is included in the realm of values. Sometimes it is true a very "long run" is required; sometimes the experience of generations is necessary before it can be discovered whether certain things are finally worth while. But there is no other test than experience. 
This field of the interaction and adjustment of the needs and claims of the single self in relation to those of other individuals constitutes what is commonly called the domain of morality. Men have attempted to set up standards, to enunciate principles that shall rule in these complex adjustments; they have formulated such rules in codes. Men of the blinder sort, seeing nothing but what is nearest, have found it difficult to appreciate the need for those rules which demand the adjustment of one's own claims to those of other individuals. To avoid the results of this blindness, men of the more farseeing sort have attempted to give artificial support to such codes by attributing them to the will of some powerful being who will punish their infraction; by setting them forth as the command of God, and to be obeyed for that reason. Such a procedure has its immediate uses in dealing with ignorant and thoughtless men. But, like all courses that leave the grounds of reality, it has great disadvantages. It places the whole matter on an artificial basis. It displaces the grounds of conduct from a consideration of what is needed for life to a consideration of what has been commanded. Says old Sir Thomas Browne, "I give no alms only to satisfie the hunger of my Brother, but to fulfil and accomplish the Will and Command of God; I draw not my purse for his sake that demands it, but His That enjoins it"; and this is a notion that still widely prevails. Such a reliance upon commands rather than upon the content of what is done leads to perversities. All things incorporated in the code of commands become 
of equal importance. The body of such commands becomes unalterable. Codes thus based upon supposed commands make permanent the judgments of early generations, not allowing for modifications by experience. They perpetuate ideals that time has discredited. They make the trivial and the ephemeral of equal weight with fundamentals. They perpetuate the judgments and prejudices of the class or group that formulated the code. They permit the introduction of ritualism and other artificialities into the code of morality. They open the door to the inclusion under morality of many things that do not tend toward promoting the fulness and adequacy of life or to the inclusion even of things that work against these.

And since the validity of all that is included in the code rests, not upon the welfare that its maxims bring to men, but upon arbitrary command, upon authority, the results when that authority is discovered to be unreal are disastrous. The whole code fails, the valid with the worthless. Knowing no basis for conduct but authority, the individual, when that authority fails, is left completely rudderless.

Again, in consequence of the inclusion of artificialities and perversities, the conventional morality at times becomes hateful to thinking men. I could name at the present time living men, of standing and character, of irreproachable conduct, whose antagonism is at once aroused against anything that is urged in the name of morality. This attitude is indeed not un- 
characteristic of modern times; the word moral is now to many a term of condemnation.

So extreme a position is doubtless an excess of reaction. But it is reaction to much that is unbiological in conventional codes. To recognize the biological basis for the distinctions of right and wrong as grounded in the love of life and in the promotion of its fulness and variety and adequacy will not solve all problems, but it avoids the perversities of conventionalized codes and makes unnecessary the extreme reactions against them. So far as the formulation of conduct into codes is necessary, these codes must at intervals be examined and corrected in relation to their effect on life; otherwise, their harm may exceed their benefit.

But the adjustment of one's own immediate needs and purposes to the equally justifiable needs and purposes of others presents situations that cannot be met in any simple or stereotyped way. No inner monitor, no conscience, can tell us in a flash the distinction of right and wrong; it is a matter for experience and knowledge. No maxim or body of maxims can guide in detail under all the complexities of life. From this interaction of our own requirements with those of others arises much of the difficulty involved in living, arises a large part of the drama of life. It makes of life a progression in which no simple rules can guide; a voyage in which the individual must continually feel his way, must recognize conflicting claims, must use his knowledge and his judgment at every point; and 
before final decision is made, must often wait for experience of the distant consequences of a course of action. The individual must not fail in the needs of his own self, for that is to defeat life. But also he must not fail to recognize the needs and purposes of others, for that too is to defeat life. Through the existence of many individuals having equal claims on life, the problem of what to do, the problem of what is right, becomes immensely complicated.

Further degrees of complication arise through the fact that the world is so constituted that some individuals, some living things, must give way to others. The fulfillment of the needs of some individuals necessarily involves thwarting the needs of some others. Promotion of fulness of life in some living things means the destruction of life for others. The animal lives on the plant. Many higher animals live by preying on lower ones.

For the decision as to what is to be done, as to what is right, this situation presents a desperate problem. Life is what is valuable; life is what is to be promoted. If it were possible for every division of the living material, every species, every individual, to flourish without limit, as has been desired in some religions, this would give a satisfactory solution of the problem. But this is not possible. Unlimited flourishing of the cholera bacillus involves the destruction of mankind. Freedom from destruction for small animals means the destruction of the great carnivores. Unlimited flourishing of all types of 
living things would soon so choke the world that none could live.

The problem of conduct, of what is to be done, must then find solution in some other direction than in promoting life for all types. There must be found some principle of selection among the existing types and individuals. This principle of selection must be consistent with the general principle that life is to be promoted, that its fulness and adequacy are the object of effort.

Such a principle of selection is found in the fact that great differences in the grade of development that life has reached are found among the many types that are striving to live. In some, life is fuller, more complex, more diversified, more adequately correlated with the rest of the universe-in a word, higher - than in others. In deciding what is to be done, the principle that life is to be promoted is to be followed for another step. The fuller, more adequate life-the higher life-is to be given preference over the lower and simpler. Since some representatives of life must give away to others, it is the lower that must give way to the higher.

This principle leads to many difficult questions, each of which has to be settled for itself on the basis of the precise given situation. It does not imply that the welfare of lower forms is to be disregarded. It does not logically lead to callousness and cruelty. It is life that is to be promoted; the lower life if it does not stand in the way of the higher; the higher life if one must give way to the other. As between man and 
a destructive bacterium, the choice is obvious. In many other cases, it is equally obvious. But situations occur in which the choice is not obvious, in which the only recourse is for the individual to use his best judgment as applied to that particular situation. So far as it is clear which is indeed the higher, which the lower, representative of life, the matter is settled. So far as there is necessary a choice between man and another organism of our earth, this principle justifies giving the preference to man. But in applying this principle, it is not to be forgotten that its essence is the promotion of life, and that one kind of life is to be sacrificed to another only when this is inevitable.

Where the difficulties become acute is in the application of this principle to diversities that are but slight or doubtful. In man there are differences of type, of race. Are some of these higher, others lower? And if this question is to be answered Yes, are the interests of the lower types of man to be sacrificed to those of the higher? Are the lower to be cut off and replaced by the higher?

Again, in any given group of men, in any nation or community, there are individuals that differ greatly; differ in their very constitutions, their inheritance. It cannot be denied that in some life is fuller and more adequate-higher-than in others. Is the higher individual to promote his life at the expense of his humbler neighbor? Is the lower individual or family to be sacrificed to the higher one? Does the study of biology lead to the divine right of the aristocrat? 
It is clear that nothing in the biological principle that life is to be promoted calls for any unnecessary sacrifice of the slightly lower to the slightly higher. There is nothing in that principle to justify the destruction of millions of men to satisfy the ambitions of a Napoleon. Nothing in it calls for a ruthless neglect and contempt for the lives and interests of the slightly lower to gratify the desires of the slightly higher. Respect and sympathy for the lives and interests of all mankind is what the principle of promoting life demands; with an issue drawn between higher and lower only when such an issue cannot be escaped.

Other things that must weigh in deciding the individual's course of action come into view when one considers the fact of progressive evolution in connection with the way in which the continuance of life is brought about. In most forms of life, after a certain period of living the existing individuals disappear; they die and are replaced by others.

This ceasing to live is an event that stands in sharp opposition to that striving for the promotion and fulness of his own life and that of his associates which is the mainspring of effort in each individual. Attempts have been made to convince the individuals that, in man at least, this change is only apparent; that, in fact, the same individuals continue to live after the event that we call death. Such a doctrine forms one of the main foundations of certain types of religion. 
We are forced, I believe, to say that biological science finds no support for such a doctrine. Life does indeed continue but in other individuals. It is toward fulness and adequacy and variety that life strives. But this is attained, perhaps quite as fully, or more fully, through the life of successive individuals as it would be through the continued life of the individuals now in existence. Continued life of the present individuals would indeed avoid the process of aging and death, which casts a shadow on the life of those existing, and in so far works aganist the fulness and adequacy of life. But we are forced to take life as we find it, and what we find is that life consists not of indefinitely continuing individuals but of successive ones. No single individual of a later generation represents any single individual of a foregoing generation. For in the processes of reproduction, the materials of life, the genes, from many earlier generations, are thrown together, and from the mixture a new combination is extracted; so that each new individual represents or continues not one but many different individuals of foregoing generations. And no individual of a later generation is found to continue the conscious personality of any individual of a previous generation, as the later hours of a single individual continue his earlier hours, through continuity of memory. The succeeding individuals are different combinations of materials, of genes, from any now existing. They have diverse characteristics, diverse characters, different personalities, from any that have before existed. And there is no evidence of the sort required for 
establishing the verifiable relations accepted in science that the individuals who have died still live as such in some other condition.

If then we are to found our outlook on the world on what we discover in the scientific study of life, we are compelled to break with the notion that personality, individual identity, continues after death. We are compelled to conclude that the individuals who have disappeared exist no more than they did before they began life, no more than they did before the species to which they belong had been produced in evolution. This I believe to be one of the fundamentals for a world outlook based on the study of biology.

This is indeed a serious verdict. If accepted, it is bound to color much of life; it is bound to affect our attitude toward the world and toward living. Many have held that this verdict must destroy all satisfac- . tion in life; that it shows life to be futile. "Oh, life as futile then as frail," said the poet, in view of this verdict. Many have held that it cuts the ground from under all distinctions of right and wrong, all systems of ethics; that it leaves no standards by which to live, no object in living.

But such conclusions are not logical inferences; they do not necessarily follow; they are but reflections of personal disappointment. When the sharpness of that disappointment has passed away, one finds standards of living, distinctions of right and wrong, an object in living-all these things-in much the same situation as before. If immediate experience finds life to be good while it lasts-as for 
many people it does-then it is good while it lasts. If the promotion of life is worth while; if the promotion of life for others is worth while-as immediate experience of many finds it to be-this verdict does not take away such values and satisfactions. Life in a series of successive individuals may be as full, as adequate, as life in single continuing individuals.

The striving for life and for its promotion that is characteristic of living things must therefore-however reluctantly-transfer its interest, so far as the distant future is concerned, to the later individuals that are to succeed those that disappear. The situation is somewhat like that portrayed in some of the religions of the East: the present individual is but the transitory representative of continuing life. In that continuing life, in the promotion of its fulness and adequacy, he may find an object for his interest. Opportunity for this is given through the fact of continued evolutionary development. The individuals of later generations differ from the individuals before existing, not only, as we have before remarked, in their personal identity, but in their characteristics and in their characters. They may be higher, or they may be lower, in the scale of life.

These relations result from the way in which the replacement of one generation by the next occurs. Before disappearing, the individual coöperates with another individual to produce new combinations of the materials of life. From these new combinations arise the new individuals that are to replace those that disappear. The new individuals, being indeed 
new combinations, are diverse from all former ones, having new sets of characteristics-structural, functional, mental. This has been fully demonstrated through the modern study of genetics. "Reproduction" is not reproduction alone; it is reproduction with a difference. The new individual produced by a given pair of parents may be superior or inferior to one or both of his parents. What the characteristics of the new individuals shall be, the fulness and adequacy of the life that they present, depends on what individuals of the previous generation have united to produce them; as well as on what particular ones of the infinite variety of germ cells that each produces have come together. If one or both of the two individuals that mate represent a full and adequate life, and particularly if the two parents supplement one another in their characteristics and powers, they may give rise to a new individual that shows marked superiority. A genius may thus arise, a man that carries life to new heights. The importance of mating, of the decision as to what mate shall be taken, has come to be instinctively recognized; it is the concern which most deeply affects the wishes and emotions of man. It alters for better or worse both his own life and that of his successors. In his Metaphysics of the Love between the Sexes, Schopenhauer long ago presented admirably many of the relations of this matter to the advancement of life. As a result of mating there may be produced lower from higher or higher from lower, depending on what matings are made. Through it, if rightly carried out, progress may be 
made; life may rise to higher levels. Connected with it, in ways not fully understood, progressive evolution takes place: such evolution as has brought man from amoeba-like ancestors.

As such evolutionary progress continues in the future, life may go far beyond its present level. It may become fuller, more differentiated, more adequate to the world-in continuation of the progress made in the past. But this progress depends upon what is done by the organisms now in existence; for man it depends upon what we do, upon the course of action of the present generation.

This gives a further criterion, the last, for what is or is not to be done; for values; for right and wrong. All value is based upon making life full and adequate. To make life fuller and more adequate in the future, to bring to actuality the potentialities of progressive evolution, to help that it shall not take the course that leads to destruction, to assist in so steering it that life in later generations shall be better-this gives an ideal for the future, an object toward which effort may be consciously directed. Such effort is a continuation, in the same direction, of the efforts to make full and adequate the life of the individual and the life of his associates; it is an effort to make still fuller and more adequate the life of his successors.

How is this to be accomplished? To answer this question is a matter for detailed study into which it is not the province of these lectures to enter. The promotion of the future fulness and adequacy of life will include the improvement of the conditions of life, in 
knowledge and invention, in hygiene, in social organization. It will include, too, such measures as have been discovered or as shall be discovered for improving the living material itself, for improving the race. This, so far as it is practicable, is the most direct method open to us for raising the level of life. It is to be done, so far as we can see now, through making better the combinations of living materials that are to develop into the new generations. This requires some control of the matings that are made, requires the prevention of the propagation of individuals that are imperfect in constitution. All this is a difficult task in our present state of knowledge and of social organization.

But in all this promotion of the fulness and adequacy of life for later generations, by whatever means, there is an unlimited field for interest, for ideals, for effort.

Thus, to sum up, the ideals of conduct, morality, ethics, grow directly out of the urge to live that is common to all organisms. Their essence lies in effort toward the advancement of life, toward the promotion of its fulness, variety, and adequacy; they are the management of life toward these ends. As life does indeed advance, more and more things are found to require consideration in this management; its aims broaden in successive steps. First, most direct, there are the needs of the single individual in the face of the difficulties presented by the world and by the existence of other individuals. Soon the urge is 
broadened to include the life of other individuals; mates, children, companions, fellow countrymen; humanity as a whole; all living things; their life, too, is of value and is to be promoted. Still further, living things come to realize that the present is but a part of life; that life may be advanced in the future; that living may go far beyond present conditions; and that to help bring this about is worthy of effort. There is no break anywhere in the development of the management of life; it is all "natural" in the same sense that the original urge to live is natural. Throughout it is life, it is living creatures-such living creatures as we see around us-that are the objects of affection and devotion and effort.

Other objects of devotion and effort are such either for the sake of their relation to life, as in the devotion to material wealth and to the arts and sciences; or they are fictive reflections of life, unreal substitutes for the actual living; aberrations of devotion from the real to the imaginary or from the concrete to the abstract. Fairies and imps, spirits and demons, divinities and gods, all are reflections of the reality that is in living things; they are beings imagined through the freedom of fancy, by distorting, exaggerating and recombining what we find actual in the representatives of life. Serpents, scorpions, bats, foxes, carnivorous beasts, maleficent men-these supply the characteristics that are recombined by fancy into demons and devils. Butterflies, beetles, elves, and birds supply the models for imps and fairies. Goddesses are constructed from the qualities that we find 
in women. The characteristics of gods are put together from the highest that we find in men and from what we see that men may become as evolutionary development continues. All these things are the shadows of which living things are the reality. It is the living creatures themselves that have the attributes that inspire wonder and devotion and effort in these reflections. The wonder and devotion and effort given to the reflections are unconscious or distorted tributes to the living reality; they become not less by consciously turning them toward the living reality.

To sum up the whole matter the study of biology leaves us with an impression of the universe that is perhaps less pessimistic than that which is sometimes presented in the name of physics. The universe is a system that in time comes to life; a system that becomes conscious of itself; a system that has feelings, ideas, interest, thoughts, knowledge, purposes. It brings forth living things, with their sensations, emotions, satisfactions, their knowledge and thought and ideals; with their powers of action, of controlling what further occurs. This production of life and its attributes is one of the revelations of the essential nature of things; something never to be forgotten in considering the properties of the elements of which the world is put together.

In bringing forth life, the universe shows itself a system that is not given complete, once for all; a system that is not stereotyped in its action, not predictable from its beginning to its end. With the pas- 
sage of time it brings forth new things; things that are ultimate in their nature, things that can be known only by experiencing them. Life itself does not appear in final form, once for all. It transforms, it develops; repeatedly and continuously it brings forth things that are new. As its sensations, emotions, ideas, knowledge, purposes, and other mental things arise, they alter the happenings in the universe; they change its methods of action, the laws of its motions. Life moves in multifarious directions, yielding variety unlimited. It progresses in certain directions toward diversification and fulness and adequacy. It is progressing in the present as it has in the past. In the future, it may be expected to advance as it has done in the past-to heights that no one can predict, to which no one can set limits. 


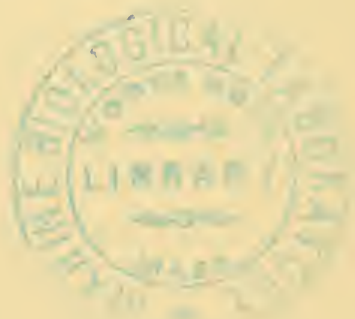






of

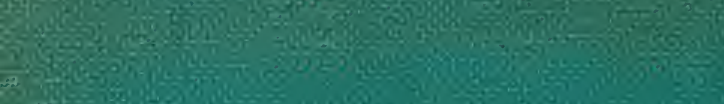

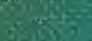
ing

1.

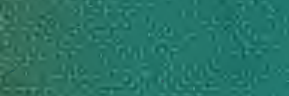

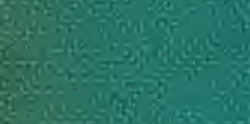

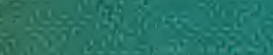

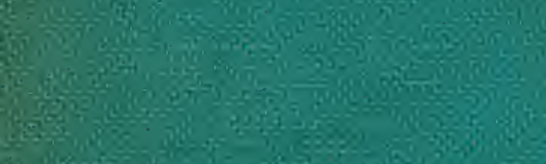

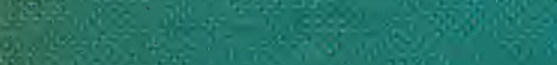
(0)

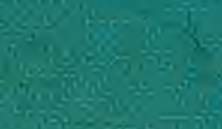

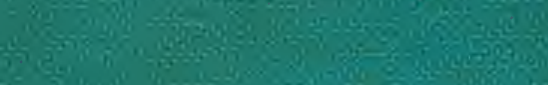

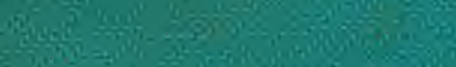$$
\begin{aligned}
& 00 \\
& 50
\end{aligned}
$$

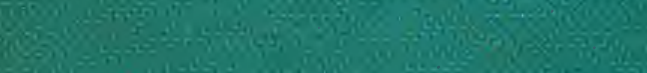

